\title{
Multi-objective optimization of combined synthesis gas
} reforming technologies

\author{
Medrano-García, J.D., Ruiz-Femenia, R. and Caballero, J.A.
}

\begin{abstract}
Synthesis gas (syngas) is a mixture of $\mathrm{H}_{2}, \mathrm{CO}$ and occasionally $\mathrm{CO}_{2}$, whose main application is as a building block of chemical compounds. The desired product dictates the syngas characteristics, which are also affected by the employed syngas synthesis technology. In this work, we study the process of producing syngas under desired specifications while consuming $\mathrm{CO}_{2}$ in the synthesis. We propose a superstructure that includes seven reforming technologies for the syngas production, as well as a variety of auxiliary units to control the final composition of the syngas. Each potential solution is assessed, in terms of the economic and environmental performance, by the Total Annualized Cost (TAC) and the Global Warming Potential (GWP) indicator. As the problem statement involves discrete decision, we use disjunctions to model the system. The resulting MINLP multi-objective problem is solved by the epsilon constraint method. Results show that at low syngas $\mathrm{H}_{2} / \mathrm{CO}$ ratios and pressures, dry methane reforming (DMR) is capable of net consuming $\mathrm{CO}_{2}$. Partial Oxidation (POX) is the technology that exhibits the minimum TAC, although shows the maximum value for the GWP. Synergistic combination of two processes allows reducing the cost and $\mathrm{CO}_{2}$-equivalent emissions through the pairing of DMR and bi-reforming (BR) and BR with steam methane reforming (SMR). Furthermore, increasing the $\mathrm{CO}_{2}$ content in the syngas at a fixed $\left(\mathrm{H}_{2}\right.$ $\left.\mathrm{CO}_{2}\right) /\left(\mathrm{CO}+\mathrm{CO}_{2}\right)$ ratio proves that TAC and GWP decrease as the $\mathrm{CO}_{2} / \mathrm{CO}$ ratio increases.
\end{abstract}

KEYWORDS: $\mathrm{CO}_{2}$ utilization, synthesis gas, methane reforming, superstructure decision making, multi-objective optimization

\section{ABBREVIATIONS}

Air separation unit

ATR

Auto thermal reforming

$B R$

Bi-reforming

CR Combined reforming

DMR

Dry methane reforming 
Heat integration

$31 \quad$ LCIA

Life Cycle Impact Assessment

32

POX

Partial oxidation

33 PSA

Pressure swing adsorption

$34 \quad \mathrm{SMR}$

Steam methane reforming

35 STAC

Specific total annualized cost

36 TAC

Total annualized cost

$37 \quad$ TR

Tri-reforming

38 WGS

Water gas shift

\section{NOMENCLATURE}

$40 \quad$ Indices

$41 \quad i$

$42 \quad j$

$43 \quad k$

$44 \quad m$

45

$46 u$

47

48

49

$50 \quad B_{k}^{1}$

$51 \quad B_{k}^{2}$

$52 \quad C_{i k}^{f}$ syngas processes: SMR, POX, ATR, CR, DMR, BR, TR

components: methane, steam/water, $\mathrm{O}_{2}, \mathrm{CO}_{2}, \mathrm{CO}, \mathrm{H}_{2}$

syngas process units: compressor, exchanger/heater/cooler, reformer reactor

post processing units: absorber1, WGS reactor, bypass1, flash, PSA, compressor, bypass2, absorber2, bypass 3

utilities: natural gas, cooling water, power 
$53 \quad C_{i k}^{v}$

$54 \quad c_{f}^{m}$

$55 \quad C_{v}^{m}$

$56 \quad F_{i k}^{P}$

$57 \quad F_{k}^{M}$

$58 \quad F_{\text {max }}$

$59 \quad I R$

$60 K_{e q}$

$61 M$

$62 n s p$

$63 \quad P_{i}$

$64 P_{\max }$

$65 P_{\text {syngas }}$

$66 T_{\text {feed }}$

$67 \quad t_{h}$

$68 T_{i}$

$69 \quad V_{a b s 1}$

$70 \quad V_{a b s 2}$

71

$72 \beta_{\text {iи }}$

$73 \quad \chi_{i j}$

$74 \delta_{j}$

$75 \varepsilon$

$76 \quad \underline{\varepsilon}$ variable cost of unit $k$ in process $i$ [\$/capacity units]

fixed cost of auxiliary unit $m$ [\$]

variable cost of auxiliary unit $m$ [\$/capacity units]

pressure factor of unit $k$

material factor of unit $k$

upper flowrate limit [kmol/h]

fractional interest rate per year

equilibrium constant for WGS reaction

stoichiometric syngas number

maximum number of existing syngas processes

operating pressure in process $i$ [bar]

upper pressure limit [bar]

target pressure of the final syngas [bar]

temperature of the stream fed to a compressor [K]

operating hours per year [h]

temperature of the stream leaving process $i$ fed its compressor [K]

volume of absorber column 1

volume of absorber column 2

cost of utility $u$ in process $i[\$ / \mathrm{kmol}$ methane fed]

conversion for component $j$ in process $i[\mathrm{kmol} j / \mathrm{kmol}$ methane fed]

cost of raw material $j[\$ / \mathrm{kmol}]$

multiobjective optimization epsilon parameter

lower bound of multiobjective optimization epsilon parameter 


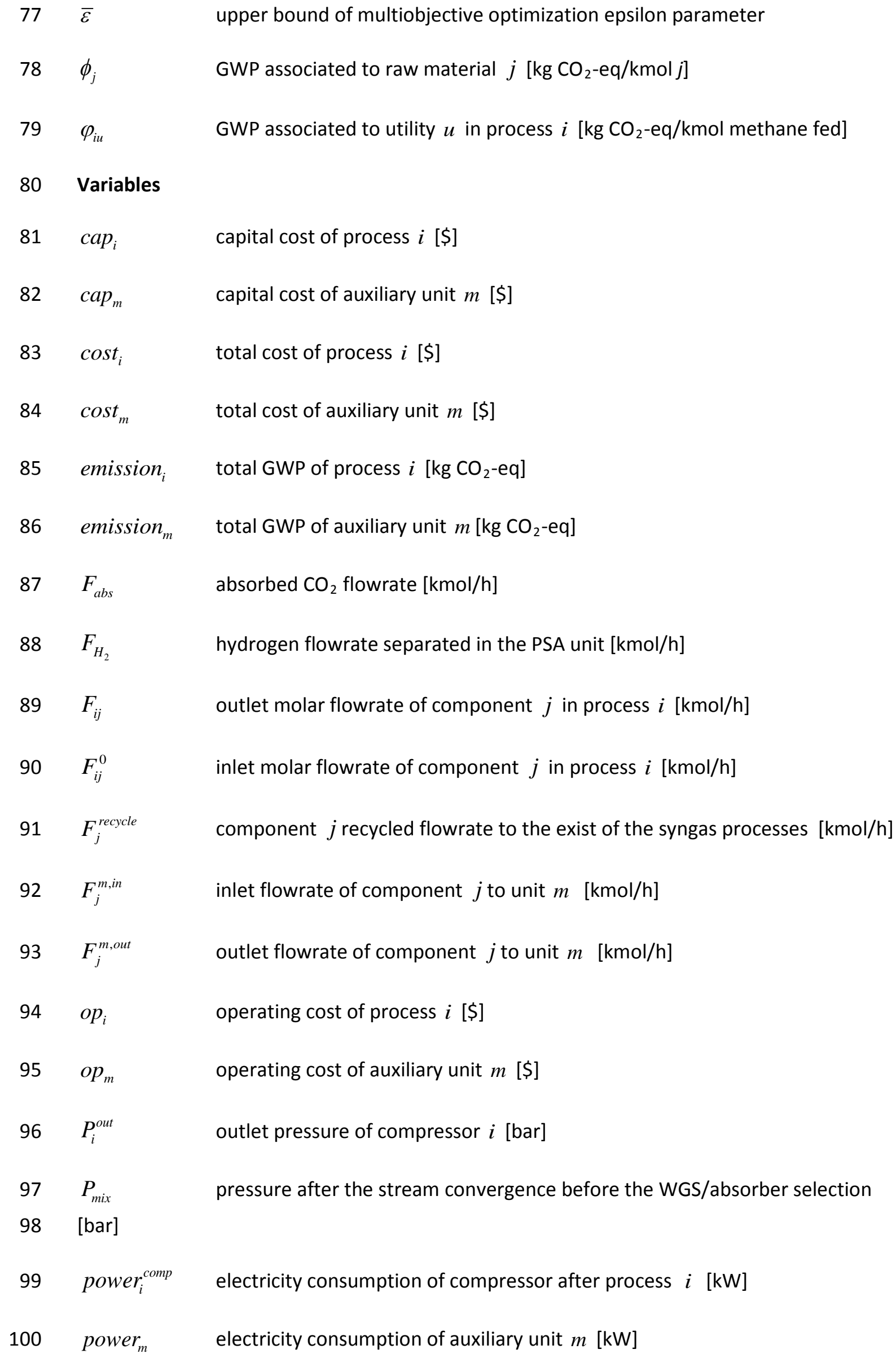




$\begin{array}{lll}101 & r a w_{i} & \text { raw material cost of process of process } i \text { [\$] } \\ 102 & y_{i} & \text { binary variable associated to the existence of process } i \\ 103 & y_{i}^{\text {comp }} & \text { binary variable associated to the existence the compressor after process } i \\ 104 & y_{m} & \text { Binary variable associated to the existence of auxiliary unit } m \\ 105 & Y_{i} & \text { Boolean variable associated to the existence the compressor after process } i \\ 106 & Y_{i}^{\text {comp }} & \\ 107 & Y_{m} & \end{array}$

110

\section{Introduction}

112 Carbon dioxide has been a matter of concern for the last decades. Its continuous and 113 increasing emission, which is almost guaranteed in any industrial process involving a chemical 114 combustion, must be controlled due to $\mathrm{CO}_{2}$ being one of the main greenhouse agents 115 originating global warming [1]. In view of this situation, the imperious need to reduce these 116 emissions has been a fact for a long time. The use of low carbon content fuels, improving 117 energy efficiency, the development of new and cleaner technologies or the increasing 118 implementation of renewable energy sources are, amongst other, different approaches made to palliate the problem [2].

120 Synthesis gas (syngas) is a mixture of gases, mainly formed by hydrogen and carbon monoxide, 121 although carbon dioxide might be also present depending on the application. Syngas can be produced by gasification or reforming of virtually any hydrocarbon source [3] and a reforming agent, like steam, oxygen, carbon dioxide or mixtures of them. Using methane as the carbon source and depending on the reforming agent or mixture of them used, syngas reforming technologies are divided into (Figure 1): steam methane reforming (SMR), partial oxidation (POX), auto thermal reforming (ATR), combined reforming (CR), dry methane reforming (DMR),

127 bi-reforming (BR), tri-reforming (TR). ATR of natural gas was first introduced by Haldor-Topsoe

$128[4,5]$ and is also the preferred reforming technology of Sasol [6, 7], Air Liquid [8], John Matthey Process Technologies [9] and BP [10] when reforming methane. On the other hand, 
POX is used by Linde, one of the major contractors of this technology world-wide, which operates the largest plant with natural gas charge (200 $00 \mathrm{Nm}^{3} / \mathrm{h}$ of syngas) [11, 12]. CR is also used as an alternative by Haldor-Topsoe [5] and Linde [11] among others, although at a lesser extent than the previous two technologies. SMR is the preferred technology when hydrogen content syngas is required or hydrogen is desired as a byproduct [13].

The "quality" of the syngas changes in each process. This property can be measured with the stoichiometric number also known as $M$, which general formula is:

$$
M=\frac{F_{\mathrm{H}_{2}}-F_{\mathrm{CO}_{2}}}{F_{\mathrm{CO}}+F_{\mathrm{CO}_{2}}}
$$

where $F_{i}$ is the molar flow (or partial pressure, concentration, etc.) in the syngas. The desired value of $M$ is not set in stone, since depending on the application it can range from almost zero (mainly $\mathrm{CO}$ when there is no $\mathrm{CO}_{2}$ ) to high values in order to get pure hydrogen (Figure 2).

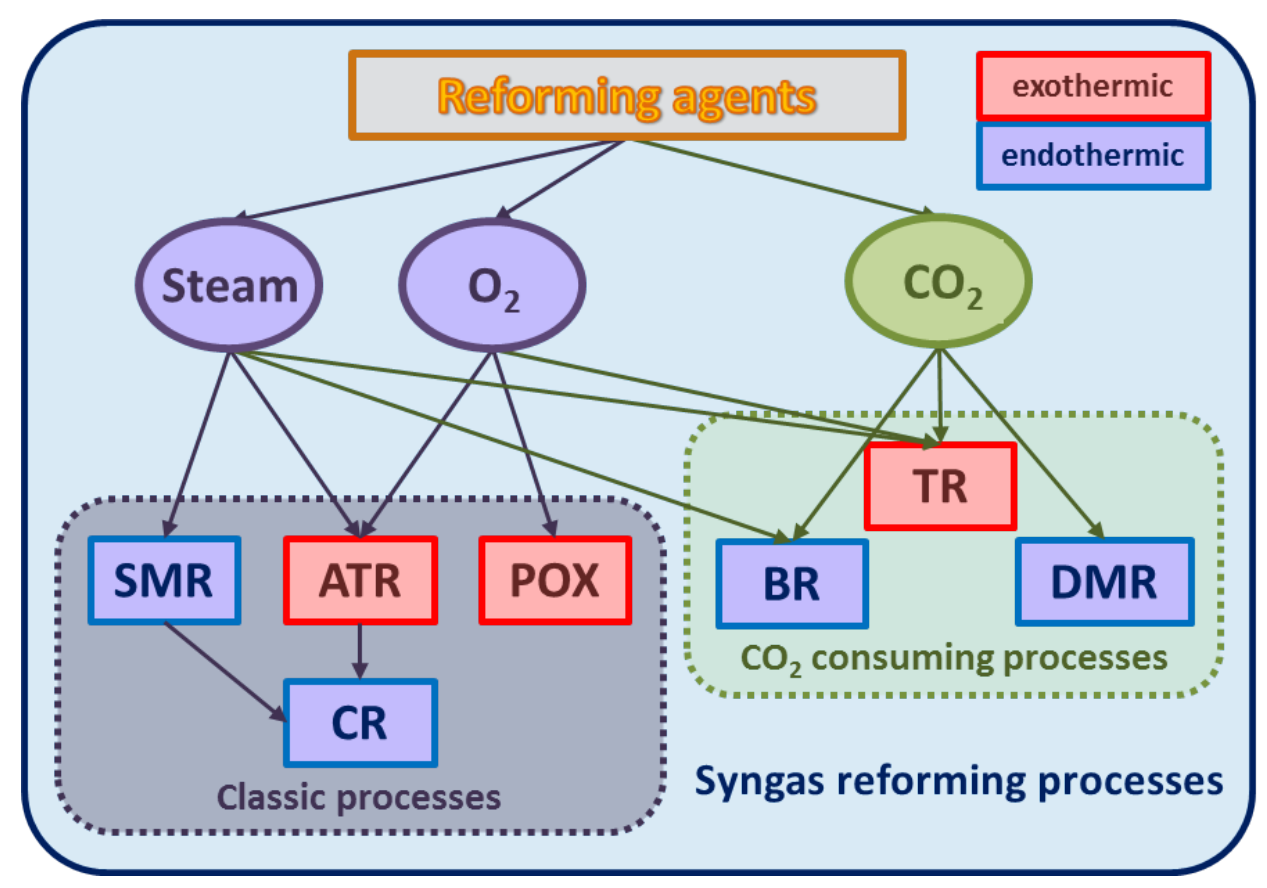

Figure 1. Syngas reforming technologies sorted by reforming agents employed. 


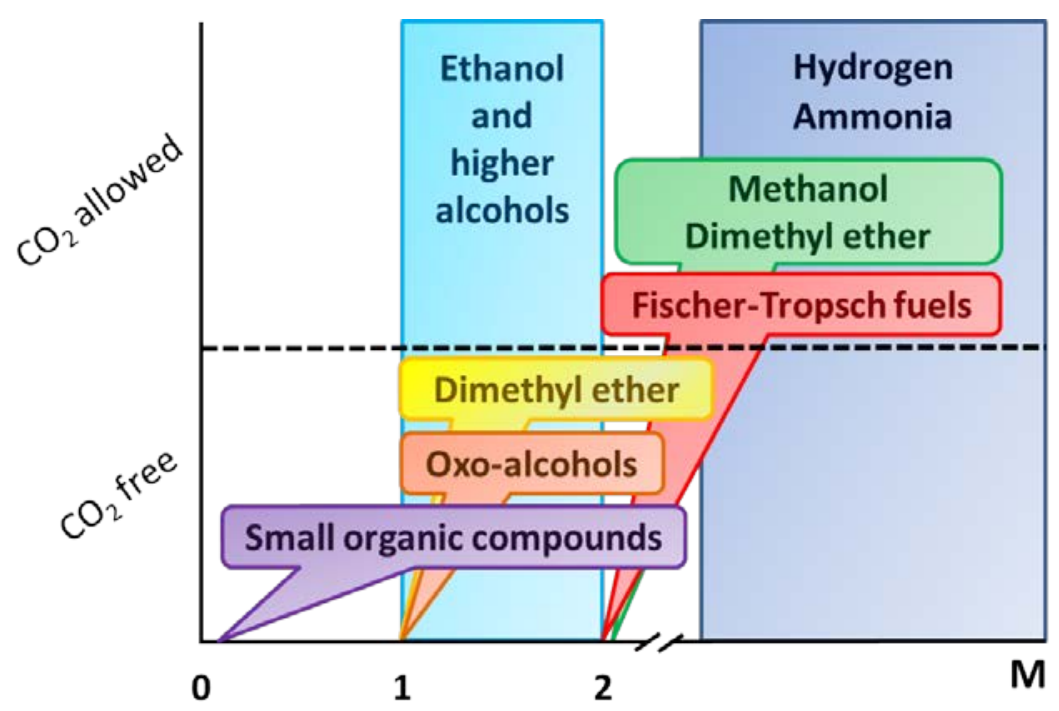

Figure 2. Downstream applications of syngas for chemical production as a function of the stoichiometric number $\mathrm{M}=\left(\mathrm{H}_{2}-\mathrm{CO}_{2}\right) /\left(\mathrm{CO}+\mathrm{CO}_{2}\right) \cdot \mathrm{CO}_{2}$ allowance in a process is optional, and in the case of hydrogen and ammonia $\mathrm{CO}_{2}$ present is not consumed.

Reforming technologies are cost intensive due to the high temperatures required to carry out the reactions (see section 2). In addition, the massive use of fuel significantly increases emissions while operating the plant. However, these aspects led to the development of the combined reforming technology [14], which uses SMR and ATR in a single process. This combination allows not only gaining more control over the $\mathrm{H}_{2} / \mathrm{CO}$ ratio but also using the exothermicity of ATR to partially fuel the SMR reactor. Several authors have studied other combinations of these technologies. Lim et al. [15] proposed a combination of SMR and DMR in which the latter used the $\mathrm{CO}_{2}$ produced in the former to increase the syngas production, successfully mitigating both cost and emissions. Farniaei et al. thermally coupled the exothermic TR with SMR and DR $[16,17]$ in concentric reactors, producing two different composition syngas flows (mixable to achieve a specific ratio) while reducing the energy consumption.

In this work, we propose a superstructure to manufacture syngas with a specific composition. This superstructure includes classic (i.e., non- $\mathrm{CO}_{2}$ consuming) and $\mathrm{CO}_{2}$ consuming reforming processes as well as a posttreatment section in which the syngas composition is further adjusted to the specified ratio. A number of composition and pressure combinations are studied to fulfill a range of syngas specifications. Multi-objective optimizations are carried out using Global Warming Potential (GWP) and the Specific Total Annualized Cost (STAC) as the objectives for just one and combination of two syngas processes. Results show that the different Pareto curves are greatly affected by the final syngas composition and pressure. 
169 Each syngas process has been designed following the scheme shown in Figure 3. An initial 170 feedstock at $25{ }^{\circ} \mathrm{C}$ and 1 bar, composed by methane or methane and a selected reforming 171 agent or mixture of them, enters a compression stage and is pressurized up to the working 172 pressure. Then, steam (as raw material) is added if necessary (Table 1 shows the available types of steam). The mixture is then preheated at the reformer furnace temperature and enters the reactor. Syngas leaving the reformer is finally cooled to $250{ }^{\circ} \mathrm{C}$ and sent to the composition adjustment stage.

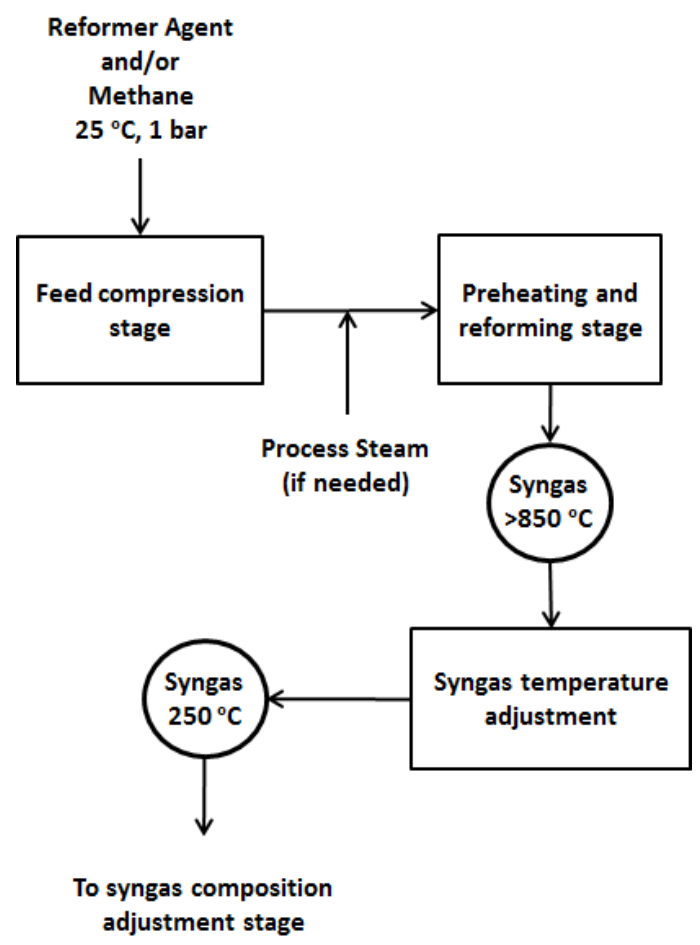

Figure 3. General syngas process flow diagram.

Table 1. Pressure, temperature and for each type of steam [18].

Low pressure $\quad$ Medium pressure High pressure

\begin{tabular}{lccc}
\hline Pressure $[\mathrm{barg}]$ & 5 & 10 & 41 \\
Temperature $\left[{ }^{\circ} \mathrm{C}\right]$ & 160 & 184 & 254 \\
Cost $[\mathbf{\$} / \mathbf{1 0 0 0 \mathrm { kg } ]}$ & 29.29 & 29.59 & 29.97
\end{tabular}


Coolers use liquid water at $30{ }^{\circ} \mathrm{C}$ leaving the exchangers at $40{ }^{\circ} \mathrm{C}$ [18]. Preheaters and reforming reactors, when needed, are fueled by natural gas combustion. It has been proved that most of the syngas processes lead to a conversion of methane near the equilibrium [16, 17, 19-25]. Consequently, and for the sake of simplicity, we carry out the simulations in Aspen HYSYS v8.4 using Gibbs equilibrium - along with the required operation units - to precalculate the conversions and the utility consumption for each technology. Optimal temperatures, pressures and feed ratios have been chosen not only to favor conversion but also to avoid real problems like soot formation or quick deactivation of catalysts. These operating conditions can be found in Table 2. Additional data, such as prices and Life Cycle Impact Assessment (LCIA) values (Global Warming Potential (GWP) for 100 years time horizon) of the raw materials are shown in Table 3. LCIA data were retrieved from the Ecoinvent environmental database [26]. In addition, Table 4 provides the prices and LCIA values for the utilities employed.

Table 2. Reforming agent/methane molar ratio in the feed stream and operating conditions for 194 each syngas process $[16,17,19-25]$.

\begin{tabular}{lccccccc}
\hline & SMR & POX & ATR & CR & DMR & BR & TR \\
\hline $\mathrm{H}_{2} \mathrm{O} / \mathrm{CH}_{4}$ & 3 & - & 1.43 & 2.5 & - & 1.6 & 2.46 \\
$\mathrm{O}_{2} / \mathrm{CH}_{4}$ & - & 0.7 & 0.6 & 0.19 & - & - & 0.47 \\
$\mathrm{CO}_{2} / \mathrm{CH}_{4}$ & - & - & - & - & 1 & 0.8 & 1.3 \\
Temperature $\left[{ }^{\circ} \mathrm{C}\right]$ & 900 & 800 & 750 & 850 & 850 & 850 & 827 \\
Pressure [bar] & 20 & 30 & 25 & 25 & 1 & 7 & 20 \\
\hline
\end{tabular}

195

196 Due to the high temperatures required to perform the reforming reactions, heat integration

197 (HI) has been implemented in order to save energy and reduce the cost and emissions related 198 to them. The SYNHEAT [27] model within GAMS has been used in order to calculate the resulting exchanger areas. The results of the $\mathrm{HI}$ analysis as well as a comparison with the base processes are shown in Table 5. Syngas processes before and after heat integration can be found in Appendix A.

202 Table 3. Prices and LCIA values for the raw materials $[28,29]$.

\begin{tabular}{cccc}
\hline Feed & Source & Price $[\mathbf{\$} / \mathbf{k g}]$ & GWP $\left[\mathbf{k g ~ C O} \mathbf{~}_{2}\right.$-eq/kg] \\
\hline Methane & $\begin{array}{c}\text { Global market }(96 \% \\
\text { volume })\end{array}$ & 0.2441 & 0.9103
\end{tabular}




$\begin{array}{cccc}\text { Steam } & \begin{array}{c}\text { Global market } \\ \text { (chemical industry) }\end{array} & \text { (see Table 1) } & 0.18302 \\ \text { Oxygen } & \begin{array}{c}\text { Cryogenic air } \\ \text { separation unit }\end{array} & 0.155 & 0.67043\end{array}$

$\begin{array}{lll}\text { Carbon dioxide } & \text { Amine absorption } & 0.04306\end{array}$

203

204 Table 4. Utility prices and LCIA values [18, 28].

\begin{tabular}{|c|c|c|c|}
\hline Utility & Source & Price $[\$ / k W h]$ & GWP $\left[\mathrm{kg} \mathrm{CO}{ }_{2}-\mathrm{eq} / \mathrm{kWh}\right]$ \\
\hline Natural gas & $\begin{array}{l}\text { Heat production at } \\
\text { industrial furnace }\end{array}$ & 0.0424 & 0.2122 \\
\hline Cooling water & $\begin{array}{l}\text { Process cooling water } \\
\left(30^{\circ} \mathrm{C} \text { to } 40 \text { or } 45^{\circ} \mathrm{C}\right)\end{array}$ & 0.0013 & - \\
\hline Electricity & High voltage & 0.1086 & 0.61365 \\
\hline
\end{tabular}

205

206 Table 5. Cooling services (CS) and heating services (HS) required before and after performing

207 heat integration (HI) (units in $\mathrm{kW}$ per kmol/h of syngas).

\begin{tabular}{lccccccc}
\hline \multicolumn{1}{c}{ Process } & SMR & POX & ATR & CR & DR & BR & TR \\
\hline Base CS & 7.02 & 9.56 & 10.39 & 7.80 & 5.282 & 5.763 & 7.27 \\
CS after HI & 1.33 & 6.67 & 5.24 & 0.40 & 0 & 1.48 & 0.52 \\
\hline \% reduced & 81 & 30 & 50 & 95 & 100 & 74 & 99 \\
\hline Base HS & 19.94 & 4.49 & 7.42 & 17.26 & 23.88 & 17.37 & 9.49 \\
HS after HI & 9.47 & 0 & 0 & 8.02 & 19.98 & 11.80 & 0.64 \\
\hline \% reduced & 52 & 100 & 100 & 53 & 16 & 32 & 90 \\
\hline
\end{tabular}

208

209

2.2. Auxiliary units

210 All the alternatives of interest for the production of syngas are embedded in the

211 superstructure proposed in Figure 4. 


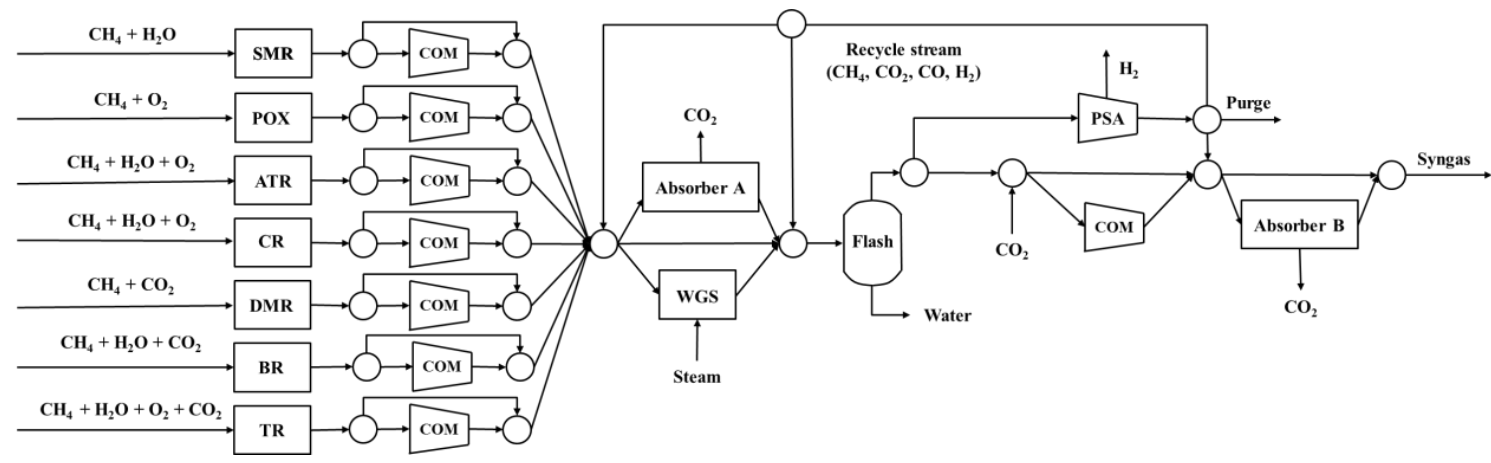

Figure 4.Proposed superstructure embedding the syngas process alternatives and specification adjustment units.

Auxiliary units are included after the main syngas process in order to adjust the syngas composition and pressure. Syngas needed for product synthesis not only requires different compositions but also pressures. For this reason, the syngas exiting the synthesis stage can be pressurized depending on the demanding pressure. Regarding the composition, a phase separator, used to remove water from syngas, is assumed to accomplish perfect separation. Hydrogen separated with the pressure swing adsorption (PSA) unit comprises $90 \%$ of the total inlet with a $99 \%$ of purity. More information and its capital cost model can be found in [3032]. Absorbers work at $40{ }^{\circ} \mathrm{C}$ and use $48 \%$ wt DGA with $96 \% \mathrm{CO}_{2}$ recovery with an operating cost of $43.06 \$ /$ ton $\mathrm{CO}_{2}$ absorbed [29]. A water gas shift (WGS) reactor is operated at $250{ }^{\circ} \mathrm{C}$ and considered capable of reaching the equilibrium, which is calculated following the equilibrium constant $\left(K_{e q}\right)$ [33]:

$$
K_{e q}=\exp \left(\frac{4577.8}{T}-4.33\right)
$$

\subsection{Mathematical modelling of the superstructure}

As can be seen in the superstructure (Figure 4), the initial feedstock enters a selected syngas process amongst the possible options, and exits the process as syngas. Since ratios methane/reforming agents, temperatures and pressures are known for each alternative (Table 2), each process can be simulated in ASPEN HYSYS v8.4 to obtain conversions and energy requirements. Conversion for component $j$ in process $i, \chi_{i j}$, is computed using this relation:

$$
F_{i j}=\chi_{i j} F_{\text {imethane }}^{0} \quad \forall i, j
$$

where $F_{i j}$ is the molar flowrate in the outlet stream of the process and $F_{\text {imethane }}^{0}$ is the molar flowrate of methane fed to the process. The values of $\chi_{i j}$ along with other calculated 
parameters employed in the model are presented in Appendix B. The total cost of a syngas process is calculated as:

$$
\operatorname{cost}_{i}=\operatorname{raw}_{i}+\operatorname{cap}_{i}+o p_{i} \quad \forall i
$$

The variable cost $_{i}$ indicates the total cost in $\$$ of process $i$, and $r a w_{i}, \operatorname{cap}_{i}$ and $o p_{i}$ are the raw material, capital and operating costs in $\$$ of process $i$, respectively, which are individually defined as:

where $\delta_{j}$, is the cost in $\$ / \mathrm{kmol}$ of raw material $j, F_{i j}^{0}$ is the initial molar flow of species $j$ in process $i, t_{h}$ is the annual operating time $(8000 \mathrm{~h}), C_{i k}^{f}(\$)$ and $c_{i k}^{v}(\$ / \mathrm{kmol}$ of raw methane) are a fixed and variable cost parameters of unit $k$ (compressor, exchanger, reactor) in process $i$. $F_{k}^{M}$ and $F_{i k}^{P}$ are the material and pressure factors of unit $k, B_{k}^{1}$ and $B_{k}^{2}$ are the bare module parameters of unit $k$ and $\beta_{i u}(\$ / \mathrm{kmol}$ of fresh methane) is the product of the energetic demand in $\mathrm{kWh}$ per $\mathrm{kmol}$ of raw methane entering the process of utility $u$ (natural gas, cooling water, power) and the cost of said utilities $(\$ / \mathrm{kWh})$. To estimate the capital cost, the required nonlinear models of Turton et al. [18] were linearized to improve the quality of the optimization (Appendix B).

The emissions in kilograms of carbon dioxide equivalent $\left(\mathrm{kg} \mathrm{CO}_{2}\right.$-eq) per hour associated to the syngas process $i\left(\right.$ emission $\left._{i}\right)$ are calculated with the expression:

$$
\text { emission }_{i}=\left(\sum_{u} \varphi_{i u} F_{\text {imethane }}^{0}+\sum_{j} \phi_{j} F_{i j}^{0}-F_{i \mathrm{CO}_{2}}^{0}\right) t_{h} \quad \forall i
$$
where the parameter $\varphi_{i u}$ represents $\mathrm{kg}$ of $\mathrm{CO}_{2}$-eq emitted of utility $u$ per kmol of methane fed to process $i$ (Appendix B), and $\phi_{j}$ the $\mathrm{kg}$ of $\mathrm{CO}_{2}$-eq emitted per kmol of raw material $j$ (Table 3). 
To handle the conditional existence or non-existence of a particular syngas process $i$, we write

261 the following disjunction:

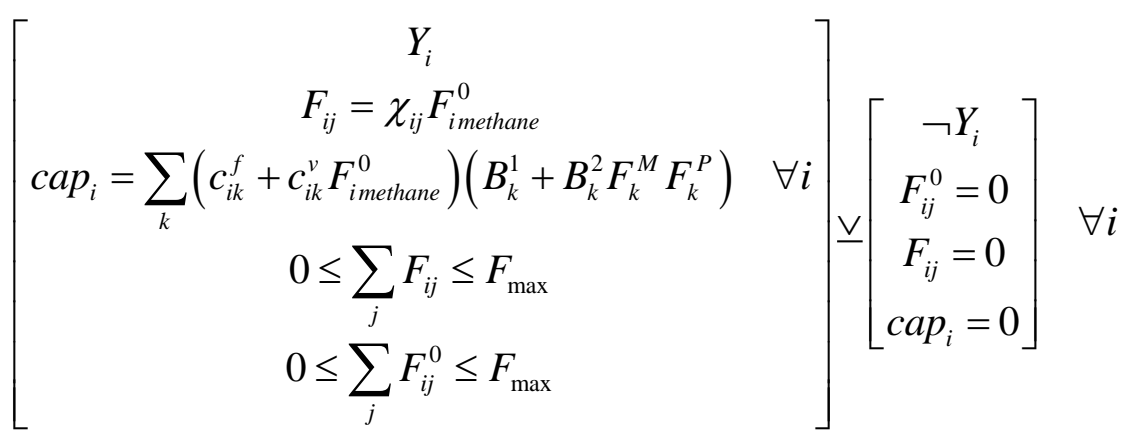

263 where $Y_{i}$ is a Boolean variable related to the existence of syngas process $i$. If the Boolean variable is true then the process has flows, costs and emissions associated to it, otherwise, all the variables associated with the process are set to zero. This disjunction can be reformulated into a set of algebraic equations using a binary variable $\left(y_{i}\right)$ which adopts the values 1 or 0 if the corresponding Boolean variable is true or false, respectively. Since all the equations enclosed in the disjunction are linear, we apply the Hull reformulation [34]. The reformulation is as follows:

$$
F_{i j}=\chi_{i j} F_{i m e t h a n e}^{0}
$$

$$
\operatorname{cap}_{i}=\sum_{k}\left(y_{i} c_{i k}^{f}+c_{i k}^{v} F_{\text {imethane }}^{0}\right)\left(B_{k}^{1}+B_{k}^{2} F_{k}^{M} F_{k}^{P}\right) \quad \forall i
$$

$$
0 \leq F_{i j} \leq y_{i} F_{\max } \quad \forall i, j
$$

$$
0 \leq F_{i j}^{0} \leq y_{i} F_{\max } \quad \forall i, j
$$

274 Moreover, to limit the number of selected syngas processes, the next equation must be included in the model:

$$
\sum_{i} y_{i} \leq n s p
$$
option of changing the pressure is given. A compressor per process may or may not exist: 


$$
\left[\begin{array}{c}
Y_{i}^{\text {comp }} \\
\operatorname{cost}_{i}^{\text {comp }}=c_{f}^{\text {comp }}+c_{v}^{\text {comp }} \text { power }_{i}^{\text {comp }} \\
0 \leq \sum_{j} F_{i j}^{c o m p} \leq F_{\max } \\
0 \leq \Delta P_{i} \leq P_{\max }
\end{array}\right] \underline{\vee}\left[\begin{array}{c}
\neg Y_{i}^{\text {comp }} \\
\operatorname{cost}_{i}^{\text {comp }}=0 \\
F_{i j}^{c o m p}=0 \\
\Delta P_{i}=0
\end{array}\right] \quad \forall i
$$

280

281

where $F_{i j}^{\text {comp }}$ is the component $j$ molar flow coming from syngas process $i$ that enters and exits its respective compressor, $P_{\max }$ is the upper limit that the pressure can reach (30 bar), $P_{i}$ is the pressure at which each syngas process $i$ operates (bar), $\Delta P_{i}$ is the increase of pressure gained in the compressor (bar) with an energy consumption ( power $_{i}^{\text {comp }}$ ) in kW calculated as:

$$
\text { power }_{i}^{\text {comp }}=\left(\frac{\gamma}{\gamma-1}\right) \eta^{-1} R_{g} T_{i} \sum_{j} F_{i j}^{\text {comp }}\left[\left(\frac{P_{i}^{\text {out }}}{P_{i}}\right)^{\left(\frac{\gamma}{\gamma-1}\right)}-1\right]
$$

where $\gamma$ is the heat capacity ratio assumed constant at $1.5, \eta$ is the compressor efficiency fixed at 0.8 and $R_{g}$ and $T_{i}$ are the universal gas constant and the inlet stream temperature respectively and $P_{i}^{\text {out }}$ is the outlet compressor pressure (bar). Applying the Hull reformulation to disjunction iError! No se encuentra el origen de la referencia. results in:

$$
\begin{gathered}
\operatorname{cost}_{i}^{\text {comp }}=c_{f}^{\text {comp }} y_{i}^{\text {comp }}+c_{v}^{\text {comp }} \text { power }_{i}^{\text {comp }} \\
0 \leq \sum_{j} F_{i j}^{\text {comp }} \leq F_{\max } y_{i}^{\text {comp }} \\
0 \leq \Delta P_{i} \leq P_{\max } y_{i}^{\text {comp }}
\end{gathered}
$$

while the outlet pressure of the potential compression stage $i$ is calculated as:

$$
P_{i}^{\text {out }}=P_{i}+\Delta P_{i}
$$

where $y_{i}^{\text {comp }}$ is a binary variable associated to the existence of the compressor. In addition, if a compressor $i$ exists then its associated process $i$ must be selected, leading to the Boolean relation:

$$
Y_{i}^{\text {comp }} \Rightarrow Y_{i}
$$


which translates into:

$$
y_{i}-y_{i}^{\text {comp }} \geq 0
$$

301

302

303

When more than one syngas process exists, the mixture of both syngas streams will result in a new stream with the lowest pressure of the two $\left(P_{\text {mix }}\right)$. Since the selected processes are unknown beforehand, the outlet pressures of the compression stage for all technologies are considered in the minimum operator:

$$
P_{\text {mix }}=\min \left(P_{1}^{\text {out }}, P_{2}^{\text {out }}, \ldots, P_{i}^{\text {out }}\right)
$$

Pressure is a decision variable with a relevant contribution both in cost and emission: the higher the target pressure is, the higher the cost and emission associated are to reach it. Therefore, when mixing the two streams, both objective functions will tend to maximize the pressure if it is let free to reduce compressor power. Since the min operator introduces a discontinuity in the model, we compute $P_{\text {mix }}$ by replacing Eq.(23) with the following set of constraints, which are suited for the optimization problem:

$$
P_{\text {mix }} \leq P_{i}^{\text {out }}+P_{\max }\left(1-y_{i}\right) \quad \forall i
$$

where $P_{m i x}$ is the final pressure after the stream mixture. According to Eq.(24), the minimum pressure of the mixture and thus, the most restrictive upper limit of $P_{m i x}$ will become the final value. After the mixture, the product syngas splits into at most three branches (Figure 4). Since all the streams reaching this point are at the same temperature (Figure 3 ), this node is modeled by a total (Eq.(25)) and component molar balances (Eqs.(26)-(28)) forcing that the concentration for each component in each stream leaving the node is the same than the average concentration of that component calculated from the two inlet streams to the node:

$$
\sum_{i} F_{i j}+F_{j}^{\text {recycle }}=F_{j}^{W G S, i n}+F_{j}^{b p 1, i n}+F_{j}^{a b s 1, i n} \quad \forall i, j
$$

$$
F_{j}^{W G S, \text { in }}\left(\sum_{i} F_{i j}+F_{j}^{\text {recycle }}\right)=\left(F_{i j}+F_{j}^{\text {recycle }}\right) \sum_{j} F_{j}^{W G S, i n} \quad \forall j
$$

$$
F_{j}^{a b s 1, i n}\left(\sum_{i} F_{i j}+F_{j}^{\text {recycle }}\right)=\left(F_{i j}+F_{j}^{\text {recycle }}\right) \sum_{j} F_{j}^{a b s 1, i n} \quad \forall j
$$


324 where $F_{j}^{\text {recycle }}$ is the molar flow recycled from the PSA unit and $F_{j}^{W G S, i n}, F_{j}^{a b s 1, i n}, F_{j}^{b p 1, i n}$ are

325 the inlet molar flows of the WGS reactor, first absorber and first bypass, respectively. These 326 nonlinear component molar balances are unavoidable in order to correctly define the splitter 327 nodes, as their absence would result in the split streams potentially having different 328 compositions. Since a structural decision must be taken from these three options, we add the 329 following disjunctions to the model. For the absorber, the disjunction results in:

$$
\left[\begin{array}{c}
Y_{a b s 1} \\
\operatorname{cost}_{a b s 1}=c a p_{a b s 1}+1.89 F_{a b s 1} t_{h} \\
0 \leq \sum_{j} F_{j}^{a b s 1, \text { in }} \leq F_{\max } \\
0 \leq \sum_{j} F_{j}^{a b s 1, \text { out }} \leq F_{\max } \\
0 \leq F_{a b s 1} \leq F_{\max }
\end{array}\right] \underline{\vee}\left[\begin{array}{c}
\neg Y_{a b s 1} \\
F_{j}^{a b s 1, \text { in }}=0 \\
F_{j}^{a b s 1, \text { out }}=0 \\
F_{a b s 1}=0 \\
\operatorname{cost} t_{a b s 1}=0
\end{array}\right]
$$

331 where $F_{j}^{a b s 1, \text { out }}$ refers to component $j$ molar flowrate exiting the absorber in $\mathrm{kmol} / \mathrm{h}, F_{a b s 1}$ is 332 the $\mathrm{CO}_{2}$ molar flow absorbed in $\mathrm{kmol} / \mathrm{h}$, cost $_{a b s 1}$ is the total cost of the absorber in $\$ / \mathrm{h}$ and 333 cap $_{a b s 1}$ is the capital cost of the absorber in $\$ / \mathrm{h}$ and has an equivalent form as Eq. (11). The 334 absorber mass balances in conjunction with the expressions resulting from applying the Hull 335 reformulation to Eq.(29) are used to model the absorber:

$$
F_{j}^{a b s 1, \text { out }}=F_{j}^{a b s 1, \text { in }} \quad \forall j \backslash\left\{C O_{2}\right\}
$$

$$
F_{\mathrm{CO}_{2}}^{a b s 1, \text { out }}=F_{\mathrm{CO}_{2}}^{a b s 1, \text { in }}-F_{a b s 1}
$$

$$
F_{a b s 1}=0.96 F_{C O_{2}}^{a b s i n}
$$

$$
\operatorname{cost}_{a b s 1}=\operatorname{cap}_{a b s 1}+1.89 F_{a b s 1} t_{h}
$$

$$
c a p_{a b 1}=\left(y_{a b s 1} c_{a b s 1}^{f}+c_{a b s 1}^{v} V_{a b s 1}\right)\left(B_{a b s 1}^{1}+B_{a b s 1}^{2} F_{a b s 1}^{M} F_{a b s 1}^{P}\right)
$$

$$
0 \leq \sum_{j} F_{j}^{a b s 1, i n} \leq F_{\max } y_{a b s 1}
$$




$$
0 \leq F_{a b s 1} \leq F_{\max } y_{a b s 1}
$$

where $y_{a b s 1}$ is the binary variable associated to the selection of absorber column 1 and $V_{a b s 1}$ is the volume of the absorber column 1 assumed as $100 \mathrm{~m}^{3}$.

For the water gas shift reactor, in order to maintain the model as simple as possible, we used the equilibrium constant (Eq.(2)) at $250^{\circ} \mathrm{C}$ along with Eq.(38):

$$
K_{\text {eq }}=\frac{F_{\mathrm{H}_{2}}^{W G, \text { out }} F_{\mathrm{CO}_{2}}^{W G S \text {,out }}}{F_{\mathrm{CO}}^{W G S, \text { out }} F_{\mathrm{H}_{2} \mathrm{O}}^{W G S \text { out }}}
$$

where $F_{j}^{W G S, o u t}$ represents the molar flow of component $j$ exiting the WGS reactor in $\mathrm{kmol} / \mathrm{h}$. Volume of the reactor is fixed at $100 \mathrm{~m}^{3}$ for capital cost calculation. The bypass is not required to be included in a disjunction since its existence is not tied to a cost, so only a simple mass balance indicating that the outlet flow $\left(F_{j}^{b p 1, \text { out }}\right)$ is the same as the inlet flow $\left(F_{j}^{b p 1, \text { in }}\right)$ is needed:

$$
F_{j}^{b p 1, \text { out }}=F_{j}^{b p 1, \text { in }} \quad \forall j
$$

The absorber, bypass and reactor can be used simultaneously and at least one of them must exist, this is represented by the logic relation:

$$
\sum_{m} y_{m} \geq 1 \quad m \in\{a b s 1, b p 1, W G S\}
$$

The flash separator removes water in a simple material balance, letting the rest of the components pass through it. Since water is present in all the alternatives, the flash separator is a mandatory unit and a disjunction is not required to model it. After drying the syngas, two choices are again encountered: a PSA unit to purify $\mathrm{H}_{2}$ and a branch which divides into a second bypass and a compressor. Again, the splitter after the flash unit is modeled using equivalent expressions to Eqs.(25)-(28). The PSA unit requires 30 bar to carry out the adsorption of hydrogen, while it is desorbed at 1 bar. The low hydrogen content syngas is considered to maintain 30 bar at the exit of the PSA. Then, this flow can return at the absorber/WGS node, continue the superstructure path and/or be purged to avoid the 
367 methane build up in the superstructure. The pure hydrogen flow is not taken into account in 368 the cost calculation. The PSA unit associated disjunction is presented in Eq.(41):

$$
\left[\begin{array}{c}
Y_{P S A} \\
\operatorname{cost}_{P S A}=\operatorname{cap}_{P S A}+o p_{P S A} \\
0 \leq \sum_{j} F_{j}^{P S A, \text { in }} \leq F_{\max } \\
0 \leq \sum_{j} F_{j}^{P S A, \text { out }} \leq F_{\max } \\
0 \leq F_{H_{2}} \leq F_{\max }
\end{array}\right] \underline{\vee}\left[\begin{array}{c}
\neg Y_{P S A} \\
F_{j}^{P S A, \text { in }}=0 \\
F_{j}^{P S A, \text { out }}=0 \\
F_{H_{2}}=0 \\
\operatorname{cost}_{P S A}=0
\end{array}\right]
$$

where $F_{\mathrm{H}_{2}}$ is the pure hydrogen flow in $\mathrm{kmol} / \mathrm{h}$ separated in the PSA. Applying the Hull reformulation and adding the mass balances lead to:

$$
\begin{aligned}
& F_{j}^{P S A, \text { out }}=F_{j}^{P S A, \text { in }} \quad \forall j \backslash\left\{H_{2}\right\} \\
& F_{\mathrm{H}_{2}}^{P S A \text { out }}=F_{\mathrm{H}_{2}}^{P S A \text {,in }}-F_{\mathrm{H}_{2}} \\
& F_{H_{2}}^{P S A, \text { out }}=0.1 F_{H_{2}}^{P S A \text {,in }} \\
& \operatorname{cost}_{P S A}=\operatorname{cap}_{P S A}+o p_{P S A} \\
& \operatorname{cap}_{P S A}=y_{P S A} C_{f}^{P S A}+c_{v}^{P S A} F_{H_{2}}^{P S A, i n} \\
& o p_{P S A}=0.1086 \text { power }_{P S A} t_{h} \\
& \text { power }_{P S A}=\left(\frac{\gamma}{\gamma-1}\right) \eta^{-1} R_{g} T_{\text {feed }} \sum_{j} F_{j}^{P S A, \text { in }}\left[\left(\frac{P_{h}}{P_{\text {out }}}\right)^{\left(\frac{\gamma}{\gamma-1}\right)}-1\right] \\
& 0 \leq \sum_{j} F_{j}^{P S A, \text { out }} \leq F_{\max } y_{P S A} \\
& 0 \leq \sum_{j} F_{j}^{P S A, i n} \leq F_{\text {max }} y_{P S A} \\
& 0 \leq F_{H_{2}} \leq F_{\text {max }} y_{P S A}
\end{aligned}
$$
bar) and inlet pressures. 
384

385

386

387

388

389

390

391

392

393

395

396

397

The branch parallel to the PSA unit, which divides into a bypass and a compressor, can be selected simultaneously with the PSA unit. However, the bypass and the compressor cannot exist at the same time. In addition, an optional $\mathrm{CO}_{2}$ stream $\left(\mathrm{F}_{\mathrm{CO}_{2}}\right)$ can be mixed before the compressor/bypass division if it is required to adjust the composition. The disjunction for the existence of the compressor can be seen in Eq.(52):

$$
\left[\begin{array}{c}
Y_{\text {comp }} \\
\operatorname{cost}_{\text {comp }}=\operatorname{cap}_{\text {comp }}+o p_{\text {comp }} \\
0 \leq \sum_{j} F_{j}^{\text {comp out }} \leq F_{\max } \\
0 \leq \sum_{j} F_{j}^{\text {comp ,in }} \leq F_{\max }
\end{array}\right] \underline{\vee}\left[\begin{array}{c}
\neg Y_{\text {comp }} \\
F_{j}^{\text {comp ,in }}=0 \\
F_{j}^{\text {comp ,out }}=0 \\
\operatorname{cost}_{\text {comp }}=0
\end{array}\right] \forall j
$$

reformulating and including the rest of the model equations:

$$
\begin{aligned}
& F_{j}^{\text {comp,out }}=F_{j}^{\text {comp,in }} \quad \forall j \\
& \operatorname{cost}_{\text {comp }}=\operatorname{cap}_{\text {comp }}+o p_{\text {comp }} \\
& \operatorname{cap}_{\text {comp }}=y_{\text {comp }} c_{f}^{\text {comp }}+c_{v}^{\text {comp }} \text { power }{ }_{\text {comp }} \\
& \text { op }_{\text {comp }}=0.1086 \text { power }_{\text {comp }} t_{h} \\
& \text { power }_{\text {comp }}=\left(\frac{\gamma}{\gamma-1}\right) \eta^{-1} R_{g} T_{\text {feed }} \sum_{j} F_{j}^{\text {comp }, \text { in }}\left[\left(\frac{P_{\text {syngas }}}{P_{\text {comp }}}\right)^{\left(\frac{\gamma}{\gamma-1}\right)}-1\right] \\
& 0 \leq \sum_{j} F_{j}^{\text {comp out }} \leq F_{\max } y_{\text {comp }} \\
& 0 \leq \sum_{j} F_{j}^{\text {comp }, \text { in }} \leq F_{\max } y_{\text {comp }}
\end{aligned}
$$

398 where $P_{\text {comp }}$ is pressure before the compressor. Since $P_{\text {syngas }}$ is a fixed value for each 399 optimization, the final pressure could be obtained even if the compressor is not chosen, for 400 this reason we add the next restriction:

$$
P_{\text {comp }} \geq P_{\text {syngas }}\left(1-y_{\text {comp }}\right)
$$


402

403

404

405

406

407

408

409

410

411

412

413

414

415

416

417

418

419

420

When $P_{\text {comp }}$ is greater or equal than $P_{\text {syngas }}$ the compressor is not needed and pressure has to be reduced (or unaltered) to fulfill the pressure constraint. However, if $P_{\text {comp }}$ is lower than $P_{\text {syngas }}$, the compressor has to exist so Eq.(60) is satisfied.

The second bypass of the superstructure, parallel to the final compressor, is modelled as the previous one:

$$
F_{j}^{b p 2, o u t}=F_{j}^{b p 2, \text { in }} \quad \forall j
$$

The exclusive existence of the compressor or the bypass is accounted as:

$$
\sum_{m} y_{m}=1 \quad m \in\{c o m p, b p 2\}
$$

On the final part of the superstructure, a second absorber (abs2) along with another bypass (bp3) are added. This additional absorber serves as the last $\mathrm{CO}_{2}$ removal tool. In case of not needing an additional $\mathrm{CO}_{2}$ removal stage, or if just a fraction of the $\mathrm{CO}_{2}$ needs to be extracted, the bypass is selected. The absorber column 2 follows the same model as the first absorber (Eqs.(30)-(37)) while the bypass is defined as the other ones (Eq.(39) and Eq.(61)). Both follow the 'at least one' relation previously described:

$$
\sum_{m} y_{m} \geq 1 \quad m \in\{a b s 2, b p 3\}
$$

After this last alternative, the final syngas molar flow with the desired composition is obtained. The Total Annualized Cost (TAC) of the system is calculated using Eq.(64):

$$
\begin{gathered}
\text { TAC }=\left(\sum_{i} c a p_{i}+\sum_{m} c a p_{m}\right) A F+\sum_{i}\left(o p_{i}+r a w_{i}\right)+\sum_{m} o p_{m} \\
A F=\frac{I R(I R+1)^{\text {years }}}{(I R+1)^{\text {years }}-1}
\end{gathered}
$$

where $A F$ is the annualization factor, the horizon time is 10 years and the interest rate $(I R)$ is set to 0.8 .

423 Global Warming Potential (GWP) is estimated as the sum of the net emissions (direct and 424 indirect) of the syngas reforming processes and auxiliary units: 


$$
G W P=\sum_{i} \text { emission }_{i}+\sum_{m} \text { emission }_{m}-F_{\mathrm{CO}_{2}}
$$

426 For both TAC and GWP calculations, a total of 8000 operating hours a year are taken into 427 account.

\subsection{Multiobjective optimization}

The overall bi-MINLP formulation can be finally expressed in compact form as follows:

$$
\min _{x, y}\{\operatorname{TAC}(x, y) ;-G W P(x, y)\}
$$

s.t. constraints

431

432

433

434

$(M 1)$

$$
\begin{array}{ll}
\text { s.t. } & \text { constraints } \\
& G W P \leq \varepsilon \\
& \underline{\varepsilon} \leq \varepsilon \leq \bar{\varepsilon}
\end{array}
$$

where the lower and upper limits of epsilon are obtained from the optimization of each separate scalar objective. We obtain the highest value for the GWP (that is $\bar{\varepsilon}$ ) by solving the

$$
(\bar{x}, \bar{y})=\underset{x, y}{\arg \min }\{T A C\}
$$

s.t. constraints

441 From the solution of problem (M1a), we calculate $\bar{\varepsilon}=G W P(\bar{x}, \bar{y})$. The best environmental 442 performance is obtained regardless of the economic aspect. Hence we obtain the lowest value 443 for the GWP (that is $\underline{\varepsilon}$ ) as the optimum value of the objective function for the next mono444 objective problem:

$$
\underline{\varepsilon}=\min _{x, y}\{G W P\}
$$

s.t. constraints 


\section{Results and discussion}

$448 \quad$ 3.1. Syngas synthesis under a single syngas technology

449 We optimized the superstructure for combinations of values of the parameters $\mathrm{H}_{2} / \mathrm{CO}(1.0$, $4501.5,2.0,2.5)$ and $P(1.0,10,20,30$ bar). The product syngas $C O$ molar flow is fixed at 0.3 $451 \mathrm{kmol} / \mathrm{s}$ and the $\mathrm{CO}_{2} / \mathrm{CO}$ ratio is limited to 0.05 . Since the quantity of syngas product is similar 452 and known between problems, we used Aspen HYSYS v8.4 to estimate molar flows and energy 453 consumptions. The variables are bounded according to these estimations. Upper bounds are 454 approximately five times higher than the calculated values. These estimated values are also 455 used to initialize the problem. The model consists in 467 equations and 357 variables, 24 of 456 which are binary variables. We used GAMS [36] to implement the model and solved it using 457 the ANTIGONE solver [37].

458 The resulting specific TAC (STAC) ( $\$ / \mathrm{kg}$ syngas) and GWP ( $\mathrm{kg} \mathrm{CO}_{2}$-eq/kg syngas) can be seen in 459 Figure 5 . In this case, the maximum number of chosen syngas synthesis technologies to solve 460 the superstructure is fixed to one.
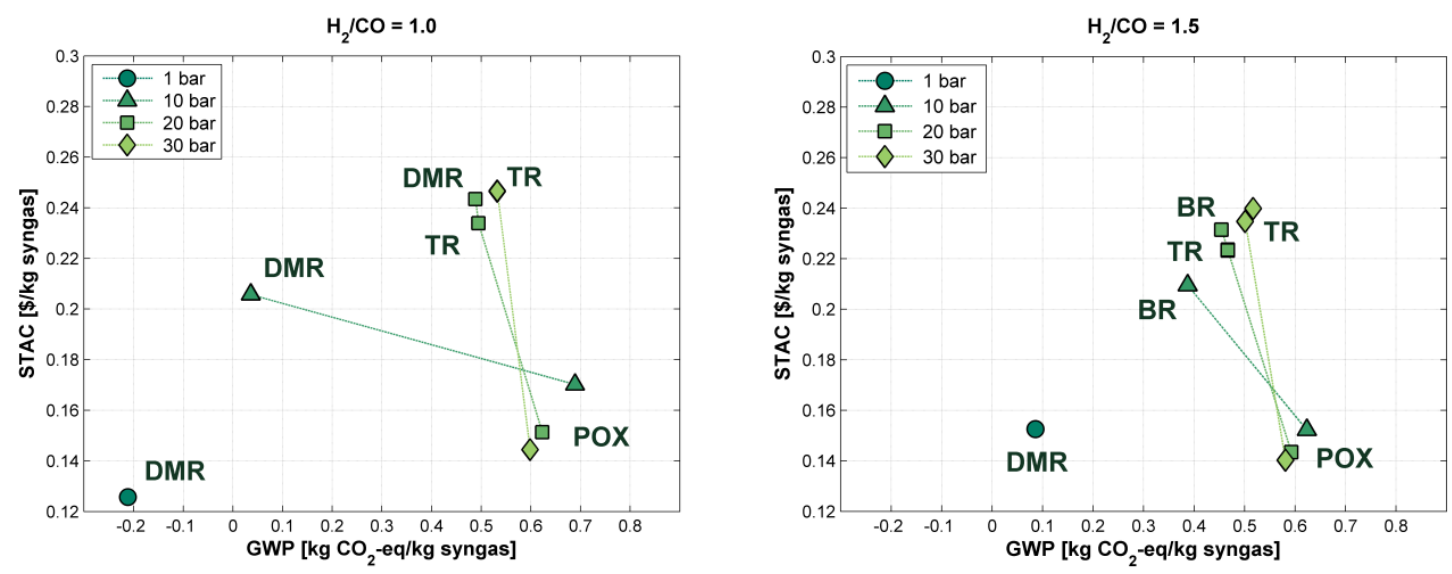

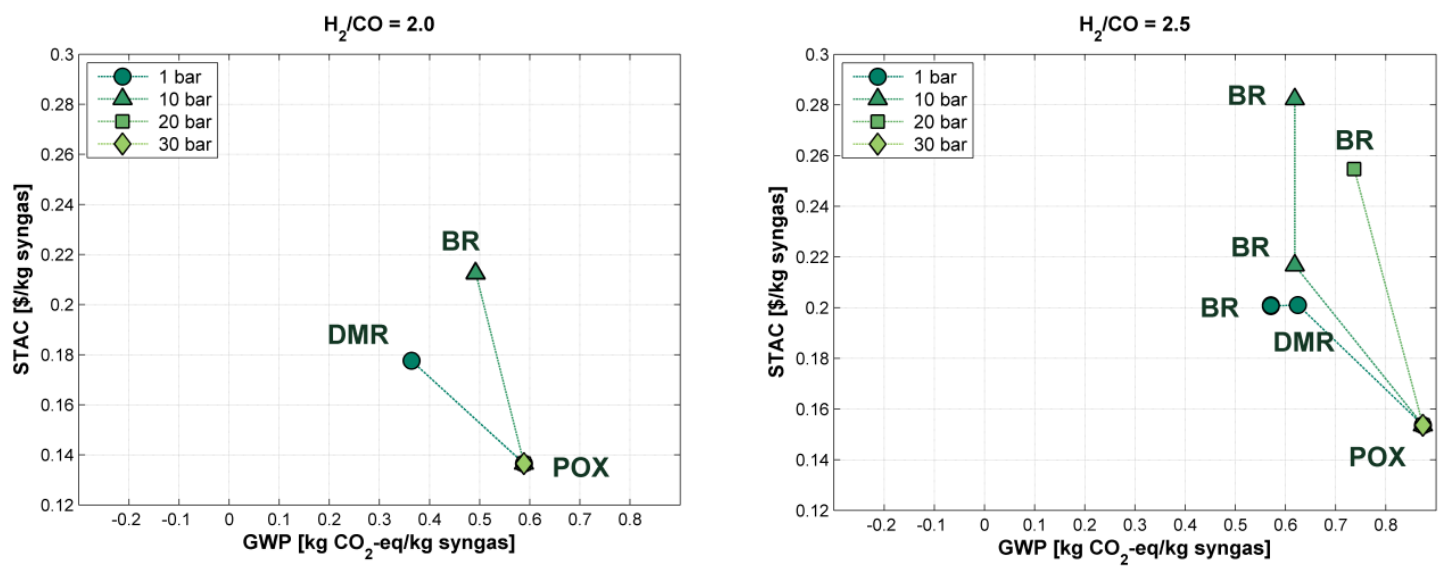

461

462

463

464

465

466

467

468

469

470

471

472

473

474

475

476

477

478

479

480

481

482

483

484

485

Figure 5.STAC-GWP Pareto set of solutions for syngas synthesis varying the product $\mathrm{H}_{2} / \mathrm{CO}$

ratio and pressure for a single syngas synthesis process.

Most of the Pareto set of solutions consist in two points (minimum STAC - maximum GWP and vice versa) due to the system being unable to find an intermediate solution configuration. In some cases, the solution consists in only one point since that particular configuration achieves both minimum STAC and GWP for the desired syngas specifications. This condition is met when aiming for a $\mathrm{H}_{2} / \mathrm{CO}$ ratio of 1.0 - 1.5 with a product pressure of 1 bar. As Figure 5 shows, DMR is single-handedly able to achieve the desired composition at these requirements with the aid of a WGS reactor (Appendix A1). The importance of this result resides in the fact that at a product pressure of $1 \mathrm{bar}$, the GWP indicator adopts a negative value of approximately $-0.2 \mathrm{~kg}$ $\mathrm{CO}_{2}$-eq/kg syngas, which means that the $\mathrm{CO}_{2}$ consumption is greater than the indirect emission of the resources employed in the synthesis. As the required pressure rises, the optimal STAC and optimal GWP points split into two different configurations. The minimum STAC is achieved by employing the POX technology and is maintained as the lower STAC option across the remaining $\mathrm{H}_{2} / \mathrm{CO}$ ratios and pressures. As can be seen in Table 5 and Figure A.4, in the POX technology and after heat integration, hot utilities are not required since raw materials can be preheated with the heat released in the reformer reactor due to the high exothermicity of the reforming reaction. This property makes POX a remarkable process costwise. In addition, for the cases where the $\mathrm{H}_{2} / \mathrm{CO}$ ratio is 2.0 and pressure is $20-30$ bar, and $\mathrm{H}_{2} / \mathrm{CO}=2.5$ and $\mathrm{P}=30 \mathrm{bar}$, both the minimum STAC and the minimum GWP configuration overlap and are led by the POX synthesis process. Regarding the minimum GWP extreme point, DMR, BR and TR (all three $\mathrm{CO}_{2}$ consuming technologies) achieve the optimal values. The first appears when low pressure is required, the last at lower $\mathrm{H}_{2} / \mathrm{CO}$ ratios and higher pressures, and the remaining one is the way to go at higher $\mathrm{H}_{2} / \mathrm{CO}$ ratios, while still being used at ratios of 1.5 . 
The difference between STAC and GWP extreme solutions is the highest at a $\mathrm{H}_{2} / \mathrm{CO}$ ratio of 487 one and a pressure of 10 bar, where an increase of approximately $20 \%$ in STAC achieves an 488 outstanding decrease of almost $95 \%$ in GWP from a maximum value of $0.7 \mathrm{~kg} \mathrm{CO}$-eq $/ \mathrm{kg}$ 489 syngas. On a second note, at a ratio of two and the same pressure, a reduction of $38 \%$ in GWP 490 while increasing the STAC a $22 \%$ is achieved. Other cases apart from the previously mentioned only achieve a slight decrease of the GWP while notably increasing the STAC.

\subsection{Syngas synthesis using a combination of syngas technologies}

In order to test a potential synergistic combination of syngas processes, the optimizations were repeated allowing a maximum of two syngas synthesis technologies and maintaining the rest of conditions stablished in section 3.1. The results are given in Figure 6. The tendencies from Figure 5 persist while the number of Pareto points for a given pressure and ratio increase, as combinations of syngas technologies can reach lower GWP configurations than single technology systems. While minimizing the emission, at $\mathrm{H}_{2} / \mathrm{CO}$ ratios of 1.0 and 1.5 , the combination of DMR and $\mathrm{BR}-$ both $\mathrm{CO}_{2}$ consuming processes - possesses the lowest GWP achievable by all these curves. As the STAC decreases - and the GWP rises - the resulting associations contain at least one $\mathrm{CO}_{2}$ consuming process, being DMR the most used (in conjunction with SMR, POX or TR) followed by TR (along with BR or POX). When the $\mathrm{H}_{2} / \mathrm{CO}$ ratio is between 2.0 and 2.5, the minimum GWP configuration for all the corresponding Pareto sets presents $B R$ and $S M R$, due to $B R$ managing to consume $\mathrm{CO}_{2}$ but producing a $\mathrm{H}_{2} / \mathrm{CO}$ ratio bellow two and SMR providing a high $\mathrm{H}_{2} / \mathrm{CO}$ ratio to compensate. For all the curves, moving in the increasing GWP and decreasing STAC direction, $\mathrm{CO}_{2}$ consuming processes can be found, such as DMR (only when $P=1$ bar) with SMR, POX or CR; TR with SMR (ratio of 2.0 and $P=20$ bar) and especially BR, combined with SMR, ATR, CR or POX. An exception for this trend is found at $\mathrm{H}_{2} / \mathrm{CO}=2.5$ and $\mathrm{P}=20$ and 30 bar. In the first pair, only a single configuration with $\mathrm{POX}$ is used for all the solutions, while the second presents a SMR + POX non- $\mathrm{CO}_{2}$ consuming association for all the intermediate points between the extreme solutions. Finally, for the ratios present POX configuration. 

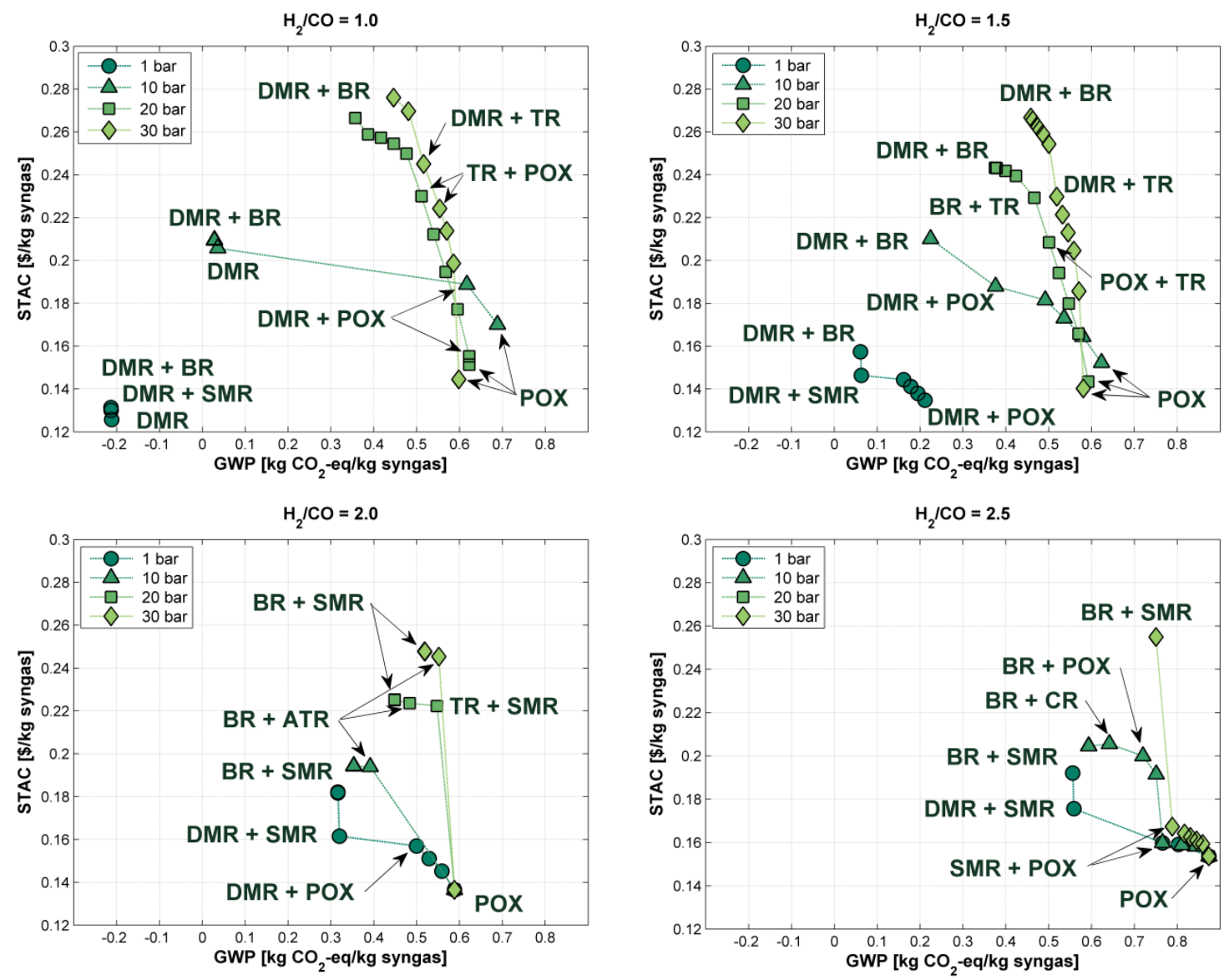

Figure 6.STAC-GWP Pareto set of solutions for syngas synthesis varying the product $\mathrm{H}_{2} / \mathrm{CO}$ ratio and pressure for the simultaneous utilization of two or less syngas synthesis processes. Unlabeled points share the same technology combination as their closest nearside labeled point that belongs to the same curve.

\subsection{Effect of the $\mathrm{CO}_{2} / \mathrm{CO}$ ratio}

519 The inclusion of $\mathrm{CO}_{2}$ in the syngas product gains interest in processes like methanol of Fischer-

520 Tropsch fuels synthesis, which under specific conditions and/or catalysts manage to consume it 521 in their main reactions. When this situation is met, the ratio of interest becomes $M=\left(\mathrm{H}_{2}-\mathrm{CO}_{2}\right)$ $522 /\left(\mathrm{CO}+\mathrm{CO}_{2}\right)$, and for the mentioned processes takes a value around two. Hence, for this study $523 M$ is fixed at two, while varying the $\mathrm{CO}_{2} / \mathrm{CO}$ ratio $(0.05,0.10,0.15,0.20,0.30,0.50)$ at a set 524 pressure of 30 bar of the product syngas. The variation in STAC and GWP of the optimized syngas synthesis process can be seen in Figure 7 . 


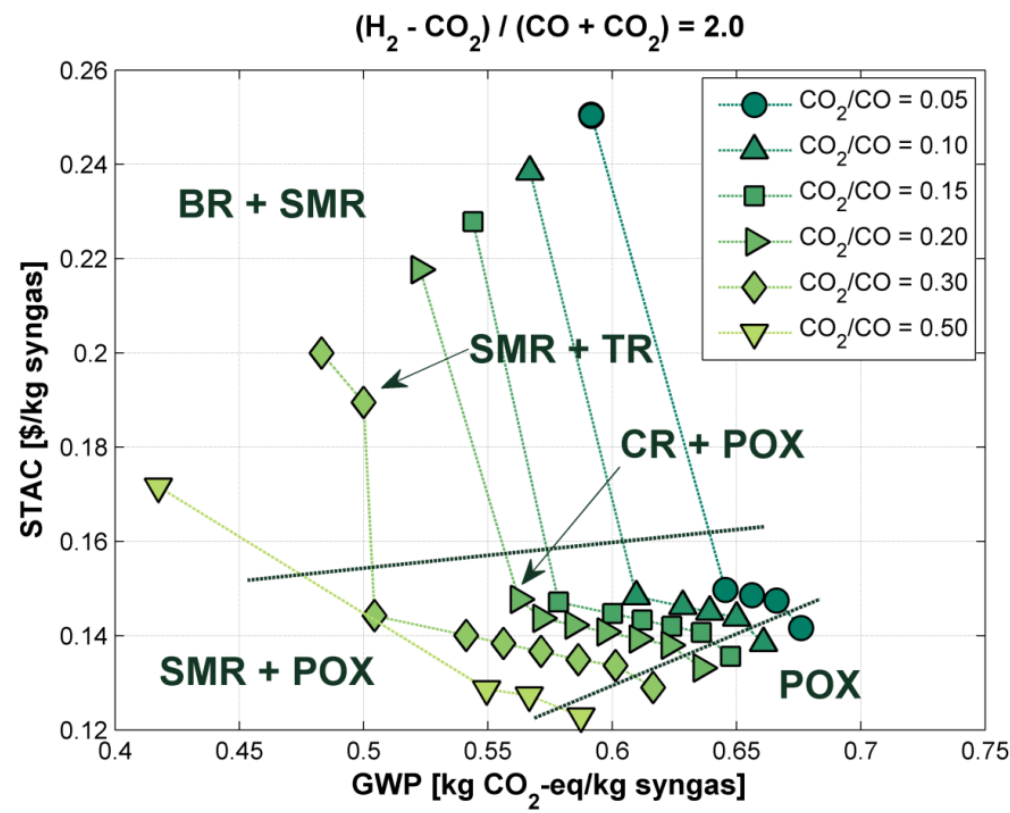

Figure 7. Pareto STAC-GWP curves at different $\mathrm{CO}_{2} / \mathrm{CO}$ ratios for a fixed product syngas pressure of 30 bar and a value of two of the $\left(\mathrm{H}_{2}-\mathrm{CO}_{2}\right) /\left(\mathrm{CO}+\mathrm{CO}_{2}\right)$ ratio with at most twosyngas process combination.

530 In Figure 6, for the combination of 30 bar and a $\mathrm{H}_{2} / \mathrm{CO}$ ratio of two, the processes used for the minimum emission configuration are BR and SMR, which after a drastic decrease in STAC, shift to SMR and POX. Finally, the minimum cost configuration is provided by POX. Two exclusive combinations appear for ratios of 0.20 and 0.30 , showcasing $C R$ and POX for the first ratio and SMR and TR for the second. The tendency is clear: increasing the $\mathrm{CO}_{2} / \mathrm{CO}$ ratio decreases both the STAC and GWP of a given syngas. Regarding the STAC-GWP trade-off, at low $\mathrm{CO}_{2} / \mathrm{CO}$ ratios, the difference in STAC when using $\mathrm{CO}_{2}$ consuming processes is high, while the net GWP itself is practically invariable. However, for a $\mathrm{CO}_{2} / \mathrm{CO}$ ratio of 0.50 , the increase in cost (30\%) and decrease in emission (31\%) could be worth a more detailed study. In Figure 8, the consumed $\mathrm{CO}_{2}$, defined as the $\mathrm{CO}_{2}$ flow entering the superstructure minus the $\mathrm{CO}_{2}$ flow leaving it by other means than the product, is plotted versus the GWP indicator. The figure shows that the minimum GWP points for all $\mathrm{CO}_{2} / \mathrm{CO}$ ratios have similar $\mathrm{CO}_{2}$ consumption, although it slightly decreases while this ratio increases. The consumption then suffers a sudden decrease even though the GWP indicator barely varies. This change addresses the importance of raw material and utility demands attached to each syngas process technology. Endothermic technologies, such as DMR, SMR or BR have high energy demands, which implies high cost and emission associated to them. However, the $\mathrm{CO}_{2}$ consuming processes (DMR, $\mathrm{BR}$ ) see their net GWP indicator reduced due to this consumption. This reduction is such that even after combining with an additional endothermic non $\mathrm{CO}_{2}$-consuming process (SMR) the association is capable 
of achieving the lowest GWP value in the studied conditions. This is why, when increasing the

550 GWP indicator (associated to a STAC reduction (Figure 7)), one of the processes (BR) shifts to a

551 low energy demand technology (POX) - which does not consume $\mathrm{CO}_{2}-$ to achieve lower costs

552 (and emissions) due to the reduced energy usage. Nevertheless, even though the energy

553 demand has been decreased, the net GWP value is higher due to the lack of $\mathrm{CO}_{2}$ reutilization.

554 Finally, for the minimum extreme points of maximum GWP configurations, consumption 555 adopts negative values, indicating that there is no reutilization of $\mathrm{CO}_{2}$ at all, or at least the 556 production of the gas surpasses its consumption.

557

558

559

560

561

562

563

564

565

566

567

568

569

570

571

572

$\left(\mathrm{H}_{2}-\mathrm{CO}_{2}\right) /\left(\mathrm{CO}+\mathrm{CO}_{2}\right)=2.0$

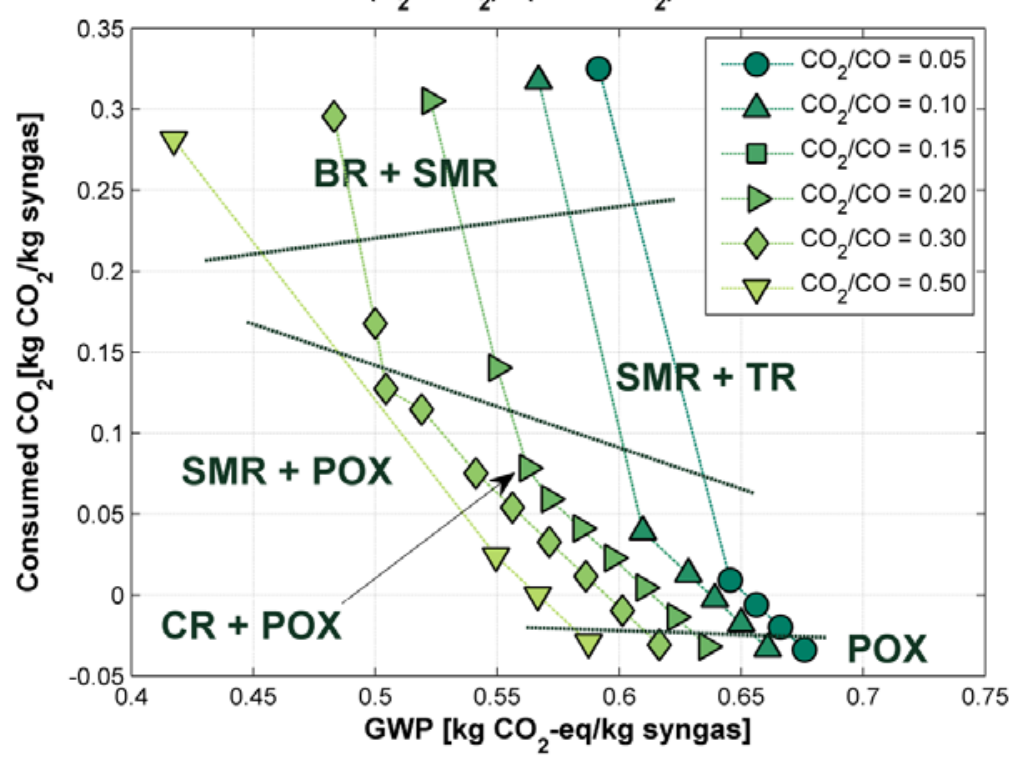

Figure 8.Effect of the consumption of $\mathrm{CO}_{2}$ versus on the net GWP per $\mathrm{kg}$ of synthesized syngas at a $\left(\mathrm{H}_{2}-\mathrm{CO}_{2}\right) /\left(\mathrm{CO}+\mathrm{CO}_{2}\right)$ ratio of two, product pressure of 30 bar and variable $\mathrm{CO}_{2} / \mathrm{CO}$ ratio with a two-syngas process combination.

\section{Conclusions}

Syngas is a mixture of $\mathrm{H}_{2}, \mathrm{CO}$ and $\mathrm{CO}_{2}$. The mixture is of great importance in the synthesis of synthetic fuels and other chemicals. The diversity of its production paths and product specifications required for its different uses makes syngas an interesting case of study, especially since $\mathrm{CO}_{2}$ can be utilized in the synthesis. In this work, we propose a superstructure containing a variety of syngas process technologies and auxiliary units in order to produce and adjust syngas to several composition and pressure specifications. The results show that at low $\mathrm{H}_{2} / \mathrm{CO}$ ratios and pressures, dry methane reforming (DMR) can net consume $\mathrm{CO}_{2}$. By contrast, all the cases indicate that POX minimizes the STAC. When allowing up to two different syngas processes to operate simultaneously, the lowest emission configurations are achieved by DMR $+\mathrm{BR}$ for a $\mathrm{H}_{2} / \mathrm{CO}$ ratio between 1.0 and 1.5 , and $\mathrm{BR}+\mathrm{SMR}$ for $\mathrm{H}_{2} / \mathrm{CO}$ ratios between 2.0 and 2.5. However, the minimum cost configurations are still achieved by using POX. 
When setting a $\left(\mathrm{H}_{2}-\mathrm{CO}_{2}\right) /\left(\mathrm{CO}+\mathrm{CO}_{2}\right)$ ratio to two, the increase of the $\mathrm{CO}_{2} / \mathrm{CO}$ ratio in the syngas shows a decrease of cost and emission. At the maximum GWP (minimum cost) configurations, $\mathrm{CO}_{2}$ is emitted with a value of $0.03-0.04 \mathrm{~kg} \mathrm{CO} / \mathrm{kg}$ syngas. However, a significant increase in the $\mathrm{CO}_{2}$ consumption is achieved with only a slight penalization in the cost. In addition, the results show that a maximum of $0.3 \mathrm{~kg} \mathrm{CO}_{2}$ per $\mathrm{kg}$ of syngas produced can be obtained with the synergistic combination of BR and SMR technologies.

\section{Acknowledgements}

The authors gratefully acknowledge financial support to the Spanish «Ministerio de Economía, Industria y Competitividad» under project CTQ2016-77968-C3-2-P (AEI/FEDER, UE).

\section{References}

584

1. European Comission, J.R.C. EDGAR - Emission Database for Global Atmospheric Research. 2015 March 2016]; Available from: http://edgar.jrc.ec.europa.eu/overview.php?v=CO2ts1990-2014.

2. Leung, D.Y.C., G. Caramanna, and M.M. Maroto-Valer, An overview of current status of carbon dioxide capture and storage technologies. Renewable and Sustainable Energy Reviews, 2014. 39(0): p. 426-443.

3. Ke Liu, C.S., Velu Subramani, Hydrogen and Syngas Production and Purification Technologies. 2010: Wiley.

4. Reyes, S.C., J.H. Sinfelt, and J.S. Feeley, Evolution of Processes for Synthesis Gas Production: Recent Developments in an Old Technology. Industrial \& Engineering Chemistry Research, 2003. 42(8): p. 1588-1597.

5. Haldor Topsoe [cited 2017 September 8th]; Available from: https://www.topsoe.com/products/autothermal-reformer-atr.

6. Sasol Technology [cited 2017 September 8th]; Available from: http://www.sasol.com/sites/sasol/files/presentations speeches/Recent\%20Adv ances\%20in\%20Sasol\%E2\%80\%99s\%20GTL\%20Technology\%20\%E2\%80\%93\%20Januar y\%202013.pdf.

7. Trevisanut, C., et al., Micro-syngas technology options for GtL. Vol. 94. 2016. n/a-n/a.

8. Air Liquid Engineering \& Construction [cited 2017 September 8th]; Available from: https://www.engineering-airliquide.com/autothermal-reforming-atr-syngas-

generation.

9. John Matthey Process Technologies [cited 2017 September 8th]; Available from: http://www.jmprotech.com/core-technologies-reforming-ATR-GHR-SMR.

10. Font Freide, J.J.H.M., et al., An Adventure in Catalysis: The Story of the BP FischerTropsch Catalyst from Laboratory to Full-Scale Demonstration in Alaska. Topics in Catalysis, 2003. 26(1): p. 3-12.

11. The Linde Group [cited 2017 September 8th]; Available from: http://www.lindeengineering.com/en/process plants/hydrogen and synthesis gas plants/gas genera tion/partial oxidation/index.html.

12. The Linde Group [cited 2017 September 12th]; Available from: https://www.hzg.de/imperia/md/content/gkss/institut fuer werkstoffforschung/wtn/ h2-speicher/funchy/funchy-2007/5 linde wawrzinek funchy-2007.pdf.

13. Haldor-Topsoe [cited 2017 September 12th]; Available from: https://www.topsoe.com/sites/default/files/topsoe large scale hydrogen produc.pd f.

14. Ullmann's Encyclopedia of Industrial Chemistry. 6th ed. 2002: Wiley - VCH. 
15. Lim, Y., et al., Optimal design and decision for combined steam reforming process with dry methane reforming to reuse $\mathrm{CO}_{2}$ as a raw material. Industrial and Engineering Chemistry Research, 2012. 51(13): p. 4982-4989.

16. Farniaei, M., et al., Simultaneous production of two types of synthesis gas by steam and tri-reforming of methane using an integrated thermally coupled reactor: Mathematical modeling. International Journal of Energy Research, 2014. 38(10): p. 1260-1277.

17. Farniaei, M., et al., Syngas production in a novel methane dry reformer by utilizing of tri-reforming process for energy supplying: Modeling and simulation. Journal of Natural Gas Science and Engineering, 2014. 20(0): p. 132-146.

18. Richard Turton, R.C.B., Wallace B. Whiting, Joseph A. Shaeiwitz, Debangsu Bhattacharyya, Analysis, Synthesis and Design of Chemical Processes. Fourth Edition ed. 2012: Prentice Hall.

19. Peña, M.A., J.P. Gómez, and J.L.G. Fierro, New catalytic routes for syngas and hydrogen production. Applied Catalysis A: General, 1996. 144(1-2): p. 7-57.

20. Bobrova, L.N., et al., Kinetic assessment of dry reforming of methane on Pt+Ni containing composite of fluorite-like structure. Applied Catalysis B: Environmental, 2016. 182: p. 513-524.

21. Julián-Durán, L.M., et al., Techno-economic assessment and environmental impact of shale gas alternatives to methanol. ACS Sustainable Chemistry and Engineering, 2014. 2(10): p. 2338-2344.

22. Lange, J.-P., Methanol synthesis: a short review of technology improvements. Catalysis Today, 2001. 64(1-2): p. 3-8.

23. Raju, A.S.K., C.S. Park, and J.M. Norbeck, Synthesis gas production using steam hydrogasification and steam reforming. Fuel Processing Technology, 2009. 90(2): p. 330-336.

24. Zahedi nezhad, M., S. Rowshanzamir, and M.H. Eikani, Autothermal reforming of methane to synthesis gas: Modeling and simulation. International Journal of Hydrogen Energy, 2009. 34(3): p. 1292-1300.

25. Olah, G.A., et al., Bi-reforming of methane from any source with steam and carbon dioxide exclusively to metgas $\left(\mathrm{CO}-2 \mathrm{H}_{2}\right)$ for methanol and hydrocarbon synthesis. Journal of the American Chemical Society, 2013. 135(2): p. 648-650.

26. Frischknecht, R., et al., The ecoinvent Database: Overview and Methodological Framework (7 pp). The International Journal of Life Cycle Assessment, 2005. 10(1): p. 3-9.

27. Yee, T.F. and I.E. Grossmann, Simultaneous optimization models for heat integrationII. Heat exchanger network synthesis. Computers \& Chemical Engineering, 1990. 14(10): p. 1165-1184.

28. Ecoinvent Database 3.3. 2017; Available from: http://www.ecoinvent.org/.

29. Nuchitprasittichai, A. and S. Cremaschi, Optimization of $\mathrm{CO}_{2}$ capture process with aqueous amines using response surface methodology. Computers \& Chemical Engineering, 2011. 35(8): p. 1521-1531.

30. Chiang, Y.C. and C.T. Chang, Single-objective and multiobjective designs for hydrogen networks with fuel cells. Industrial and Engineering Chemistry Research, 2014. 53(14): p. 6006-6020.

31. Wu, B., et al., Assessment of the energy consumption of the biogas upgrading process with pressure swing adsorption using novel adsorbents. Journal of Cleaner Production, 2015. 101: p. 251-261.

32. Ribeiro, A.M., J.C. Santos, and A.E. Rodrigues, PSA design for stoichiometric adjustment of bio-syngas for methanol production and co-capture of carbon dioxide. Chemical Engineering Journal, 2010. 163(3): p. 355-363. 

Figure A. 1. Proposed steam methane reforming (SMR) basic process.

33. Smith R J, B., M. Loganathan, and M.S. Shantha, A review of the water gas shift reaction kinetics. International Journal of Chemical Reactor Engineering, 2010. 8.

34. Lee, S. and I.E. Grossmann, New algorithms for nonlinear generalized disjunctive programming. Computers \& Chemical Engineering, 2000. 24(9-10): p. 2125-2141.

35. Ehrgott, M. and M.M. Wiecek, Multiobjective programming, in International Series in Operations Research and Management Science. 2005. p. 667-722.

36. GAMS Development Corporation. General Algebraic Modeling System (GAMS) Release 24.8.1. Washington, DC, USA, 2016.

37. Misener, R. and C.A. Floudas, ANTIGONE: Algorithms for coNTinuous / Integer Global Optimization of Nonlinear Equations. Journal of Global Optimization, 2014. 59(2): p. 503-526.

\section{APPENDIX A}

- Syngas processes before and after heat integration.

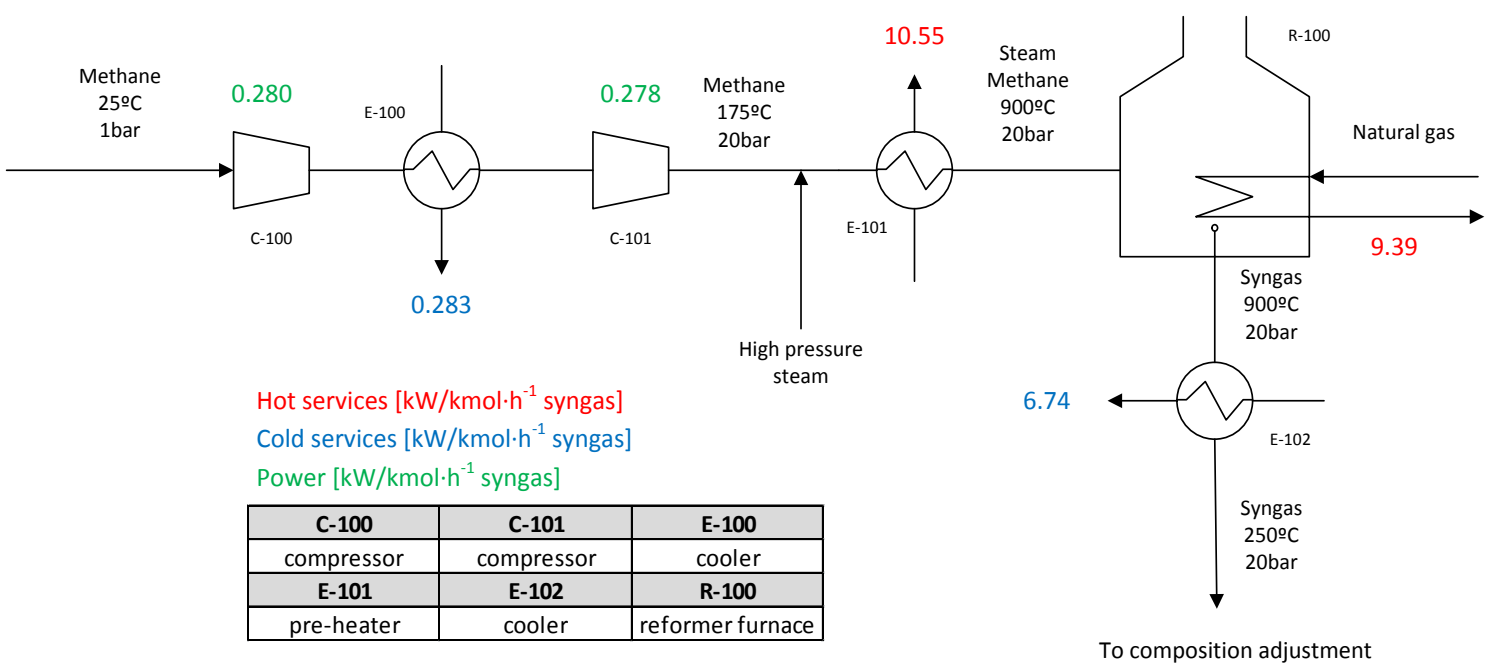

689 


\begin{tabular}{|c|c|c|c|c|c|c|}
\hline C-100 & C-101 & E-100 & E-101 & E-102 & E-103 & R-100 \\
\hline compressor & compressor & cooler & pre-heater & pre-heater & cooler & reformer furnace \\
\hline
\end{tabular}

Hot services $\left[\mathrm{kW} / \mathrm{kmol} \cdot \mathrm{h}^{-1}\right.$ syngas]

Cold services $\left[\mathrm{kW} / \mathrm{kmol} \cdot \mathrm{h}^{-1}\right.$ syngas]

Power $\left[\mathrm{kW} / \mathrm{kmol} \cdot \mathrm{h}^{-1}\right.$ syngas $]$

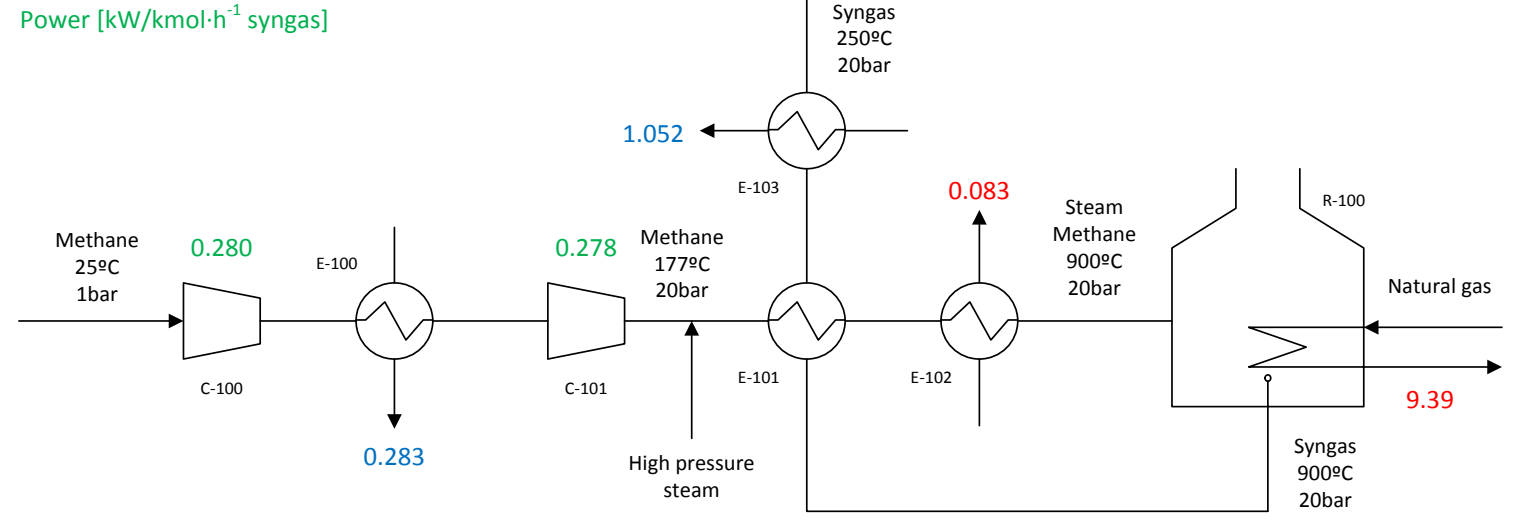

Figure A. 2. Proposed steam methane reforming (SMR) process after heat integration.

\begin{tabular}{|c|c|c|c|c|}
\hline C-100 & C-101 & C-102 & C-103 & E-100 \\
\hline compressor & compressor & compressor & compressor & cooler \\
\hline E-101 & E-102 & E-103 & R-100 & \multirow{2}{*}{} \\
\cline { 1 - 3 } cooler & pre-heater & cooler & reformer furnace & \multicolumn{1}{|c|}{}
\end{tabular}

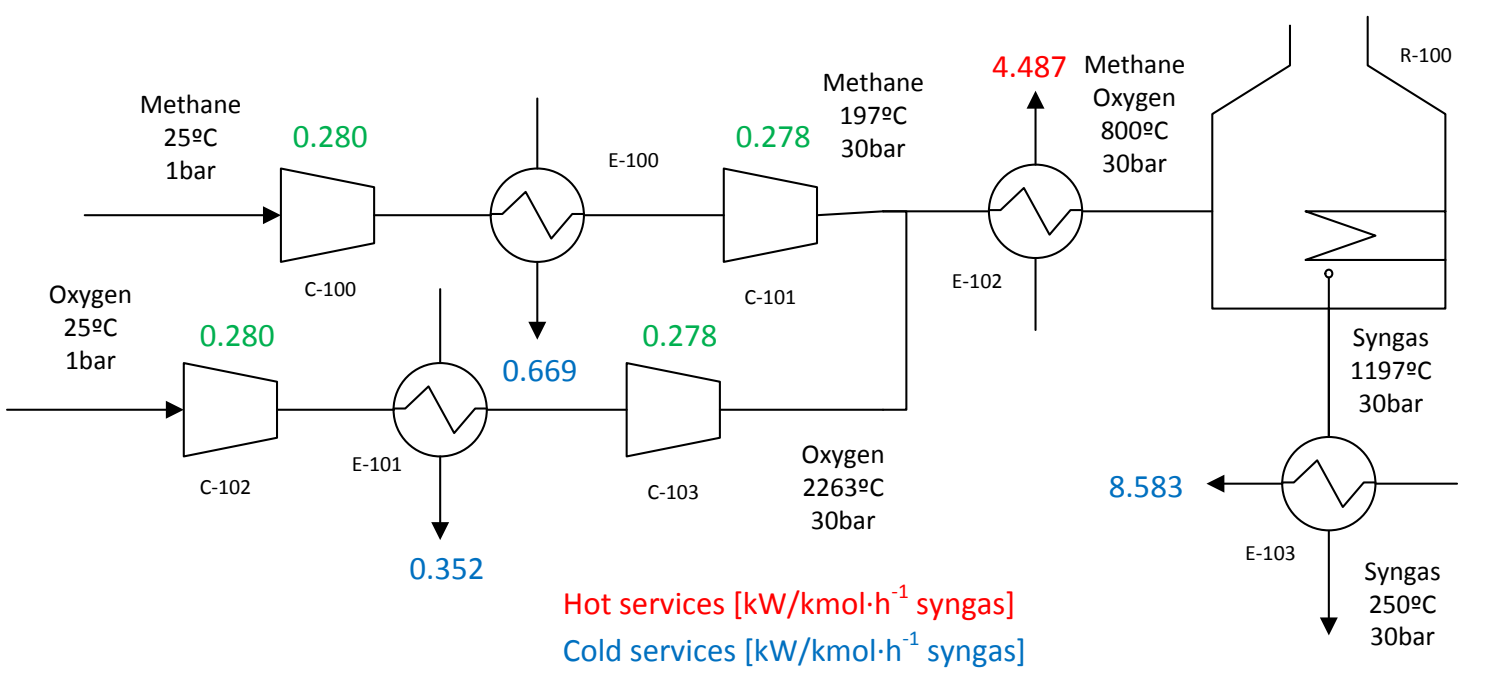

Cold services $\left[\mathrm{kW} / \mathrm{kmol} \cdot \mathrm{h}^{-1}\right.$ syngas]

Power $\left[\mathrm{kW} / \mathrm{kmol} \cdot \mathrm{h}^{-1}\right.$ syngas]

To composition adjustment 


\begin{tabular}{|c|c|c|}
\hline C-100 & C-101 & C-102 \\
\hline compressor & compressor & compressor \\
\hline C-103 & E-100 & E-101 \\
\hline compressor & cooler & cooler \\
\hline E-102 & E-103 & R-100 \\
\hline pre-heater & cooler & reformer furnace \\
\hline
\end{tabular}

Cold services $\left[\mathrm{kW} / \mathrm{kmol} \cdot \mathrm{h}^{-1}\right.$ syngas]

Power $\left[\mathrm{kW} / \mathrm{kmol} \cdot \mathrm{h}^{-1}\right.$ syngas]

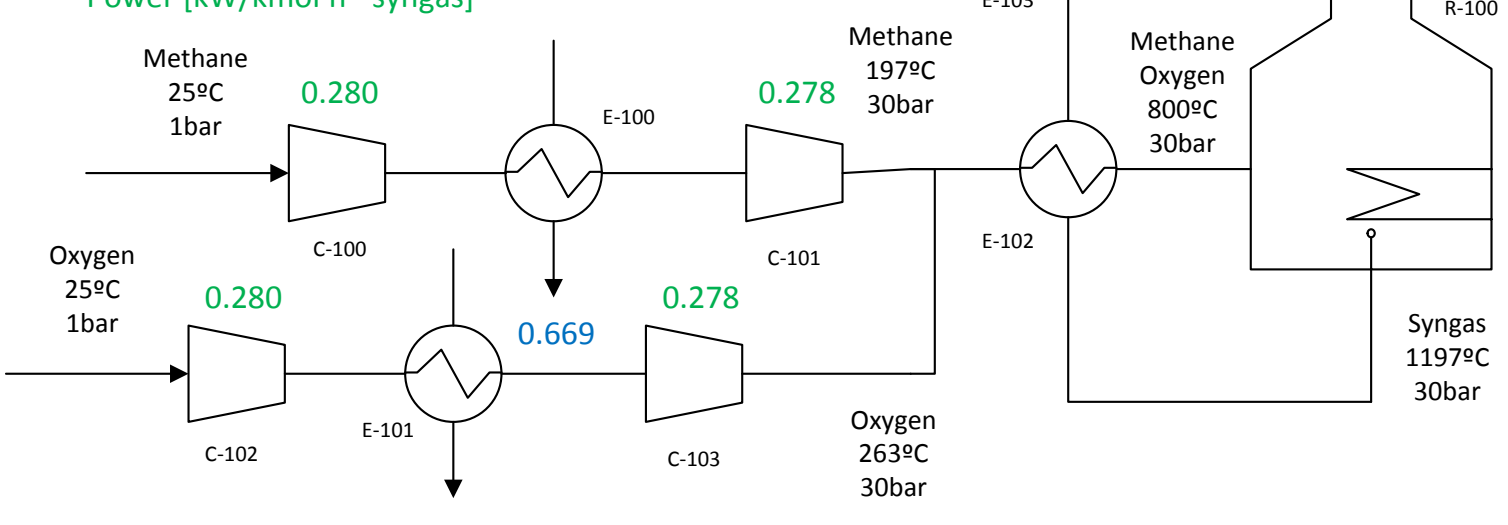

0.352

Figure A.1. Proposed partial oxidation (POX) process after heat integration.

\begin{tabular}{|c|c|c|c|c|}
\hline C-100 & C-101 & C-102 & C-103 & E-100 \\
\hline compressor & compressor & compressor & compressor & cooler \\
\hline E-101 & E-102 & E-103 & R-100 & \multicolumn{1}{|c}{} \\
\hline cooler & pre-heater & cooler & reformer furnace & \multicolumn{1}{|c}{} \\
\cline { 1 - 3 }
\end{tabular}

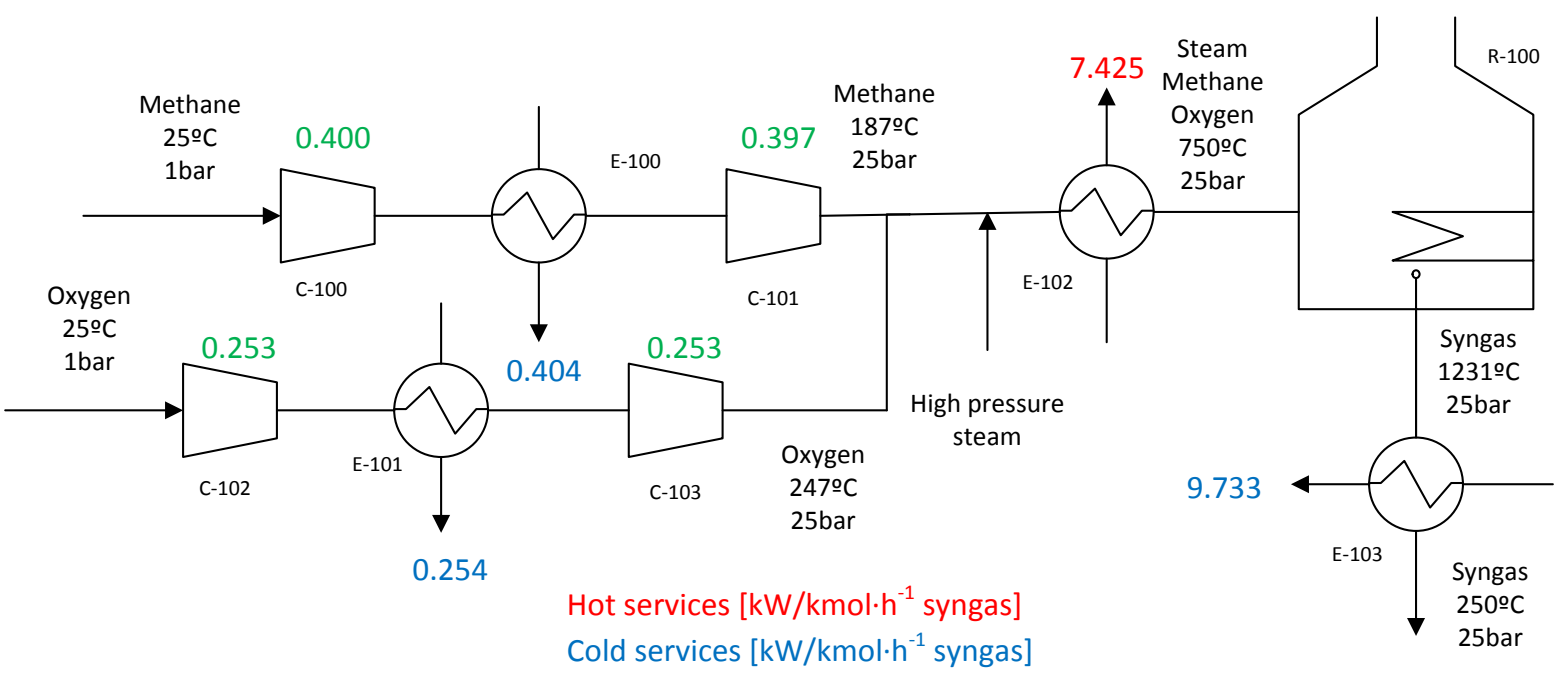

Cold services $\left[\mathrm{kW} / \mathrm{kmol} \cdot \mathrm{h}^{-1}\right.$ syngas]

Power $\left[\mathrm{kW} / \mathrm{kmol} \cdot \mathrm{h}^{-1}\right.$ syngas]

To composition adjustment 


\begin{tabular}{|c|c|c|}
\hline C-100 & C-101 & C-102 \\
\hline compressor & compressor & compressor \\
\hline C-103 & E-100 & E-101 \\
\hline compressor & cooler & cooler \\
\hline E-102 & E-103 & R-100 \\
\hline pre-heater & cooler & reformer furnace \\
\hline
\end{tabular}

To composition adjustment

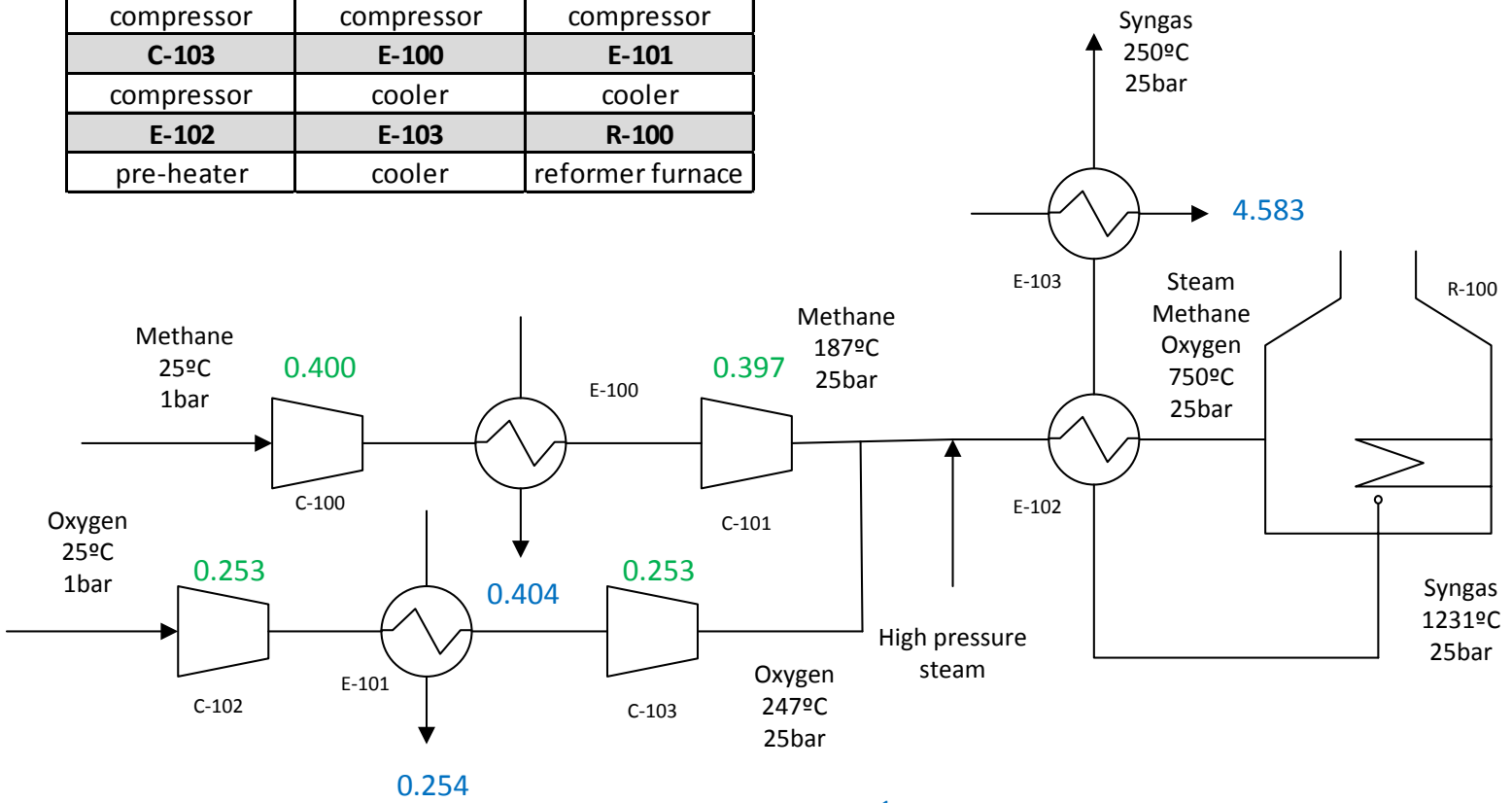

0.254

Cold services $\left[\mathrm{kW} / \mathrm{kmol} \cdot \mathrm{h}^{-1}\right.$ syngas $]$

Power $\left[\mathrm{kW} / \mathrm{kmol} \cdot \mathrm{h}^{-1}\right.$ syngas]

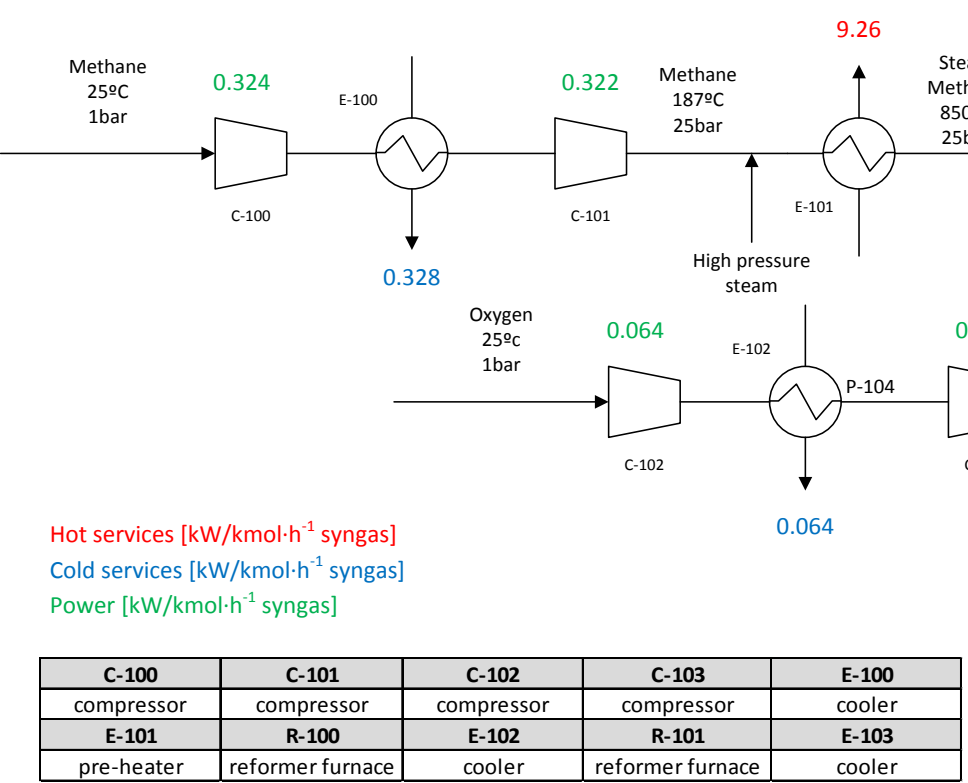




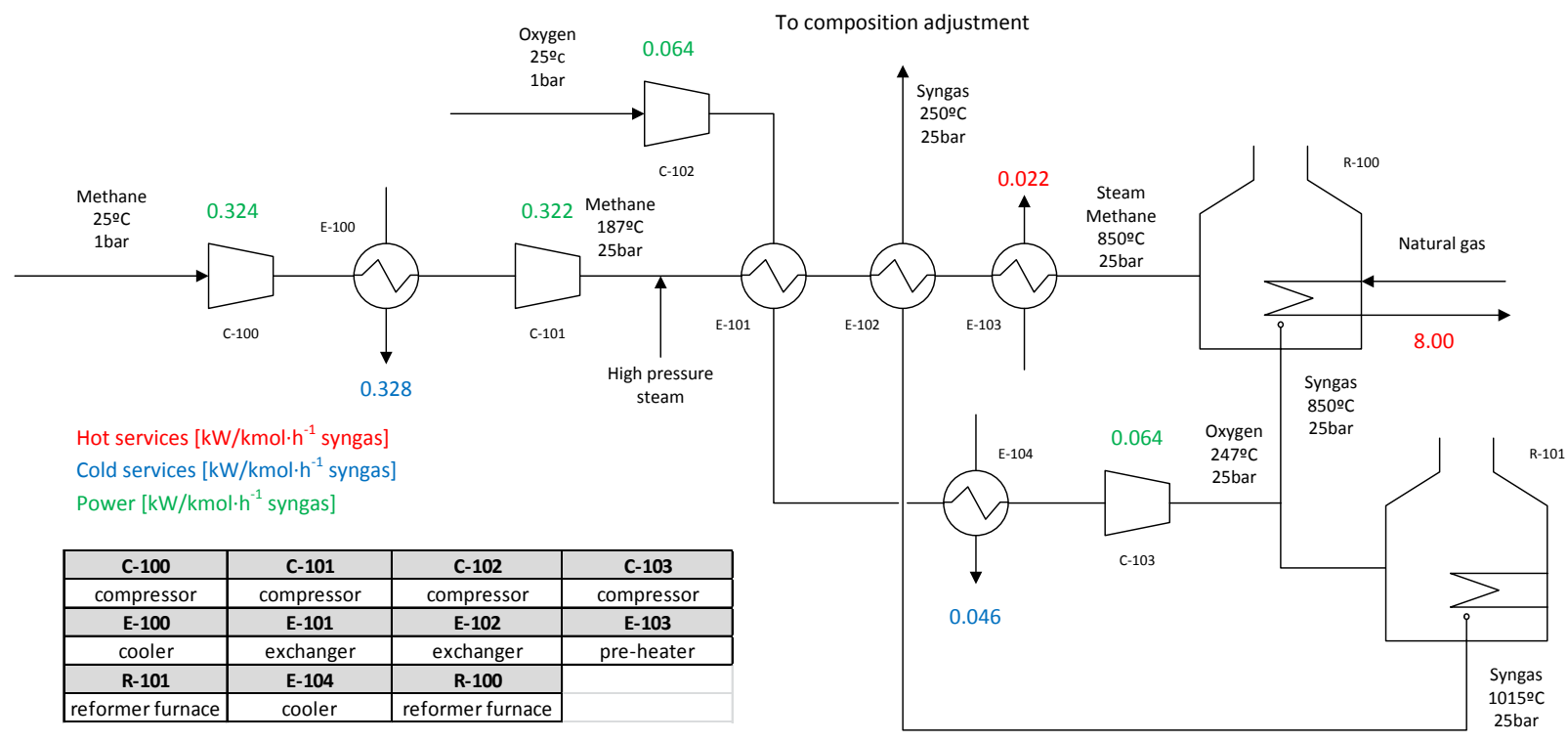

715

\begin{tabular}{|c|c|c|}
\hline E-100 & E-101 & R-100 \\
\hline pre-heater & cooler & reformer furnace \\
\hline
\end{tabular}

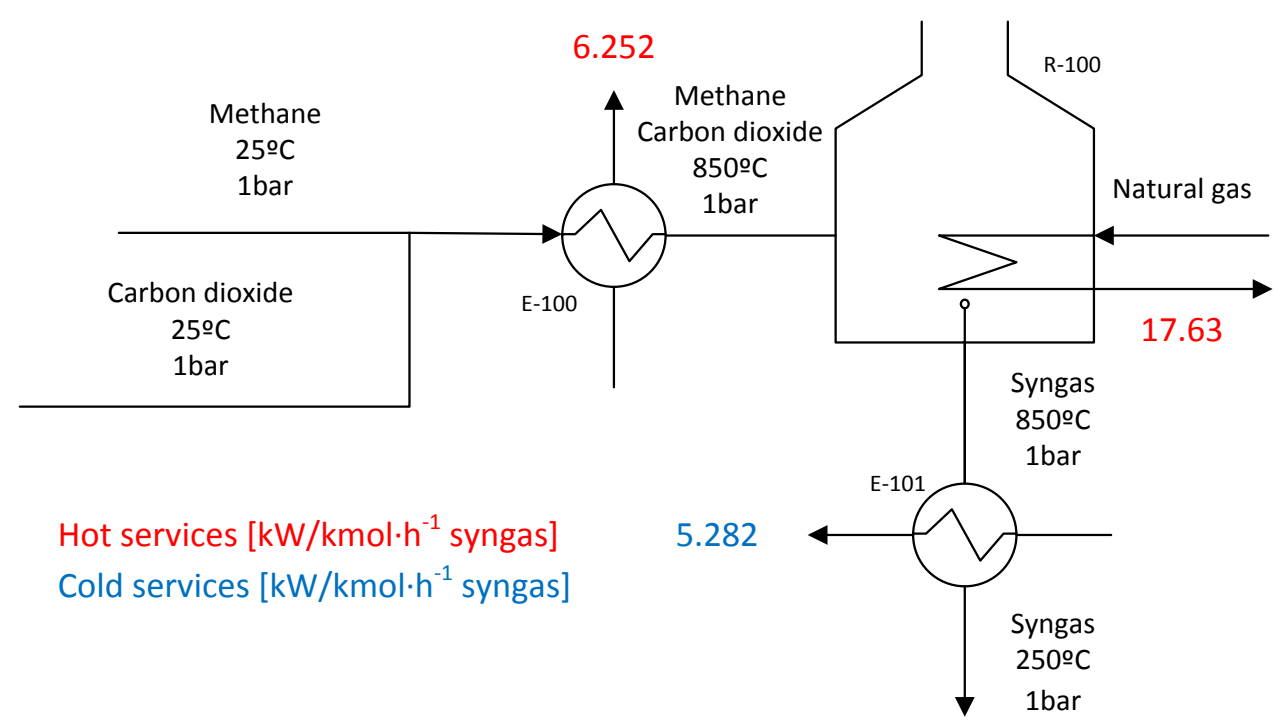

To composition adjustment

719 


\begin{tabular}{|c|c|c|}
\hline E-100 & E-101 & R-100 \\
\hline pre-heater / cooler & pre-heater & reformer furnace \\
\hline
\end{tabular}

To composition adjustment

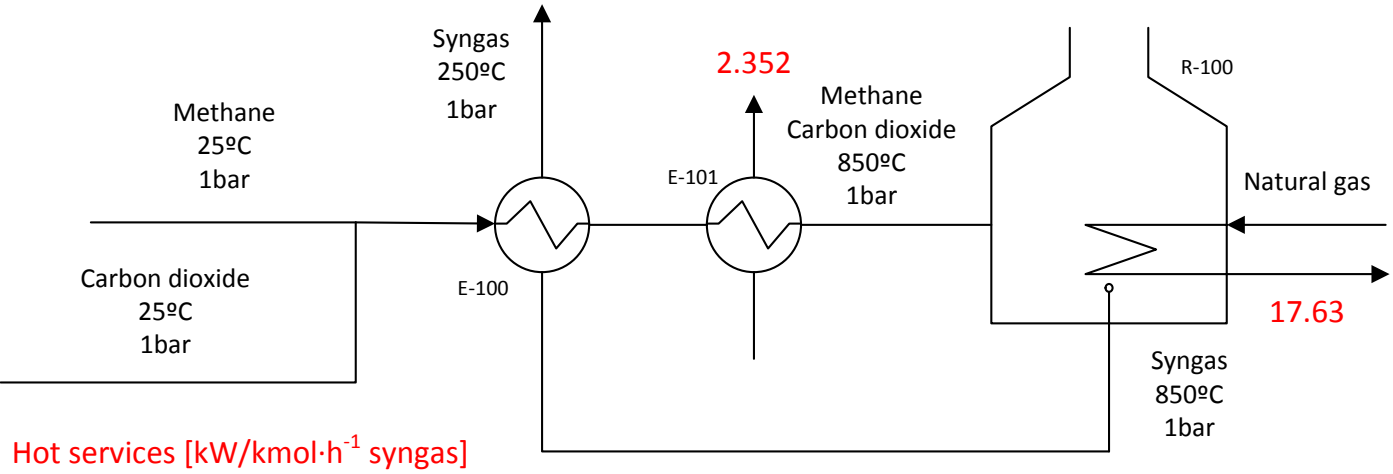

Figure A.7. Proposed dry methane reforming (DMR) after heat integration.

\begin{tabular}{|c|c|c|c|c|}
\hline C-100 & C-101 & E-100 & E-101 & R-100 \\
\hline compressor & compressor & pre-heater & cooler & reformer furnace \\
\hline
\end{tabular}

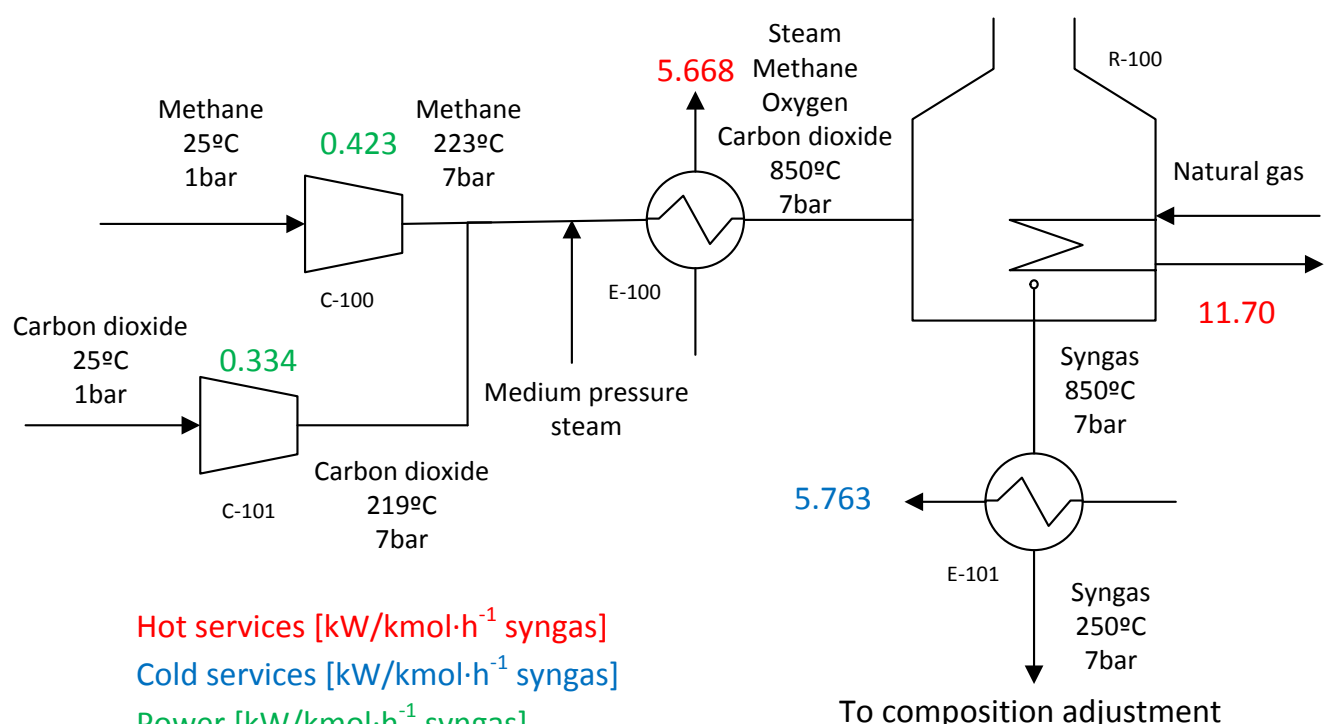

727

Figure A.8. Proposed bi-reforming (BR) basic process. 


\begin{tabular}{|c|c|c|c|c|c|}
\hline C-100 & C-101 & E-100 & E-101 & E-102 & R-100 \\
\hline compressor & compressor & pre-heater & cooler & pre-heater & reformer furnace \\
\hline
\end{tabular}

Figure A.9. Proposed bi-reforming (BR) process after heat integration.

Hot services $\left[\mathrm{kW} / \mathrm{kmol} \cdot \mathrm{h}^{-1}\right.$ syngas] Cold services $\left[\mathrm{kW} / \mathrm{kmol}^{-1} \mathrm{~h}^{-1}\right.$ syngas] Power $\left[\mathrm{kW} / \mathrm{kmol} \cdot \mathrm{h}^{-1}\right.$ syngas $]$

To composition adjustment
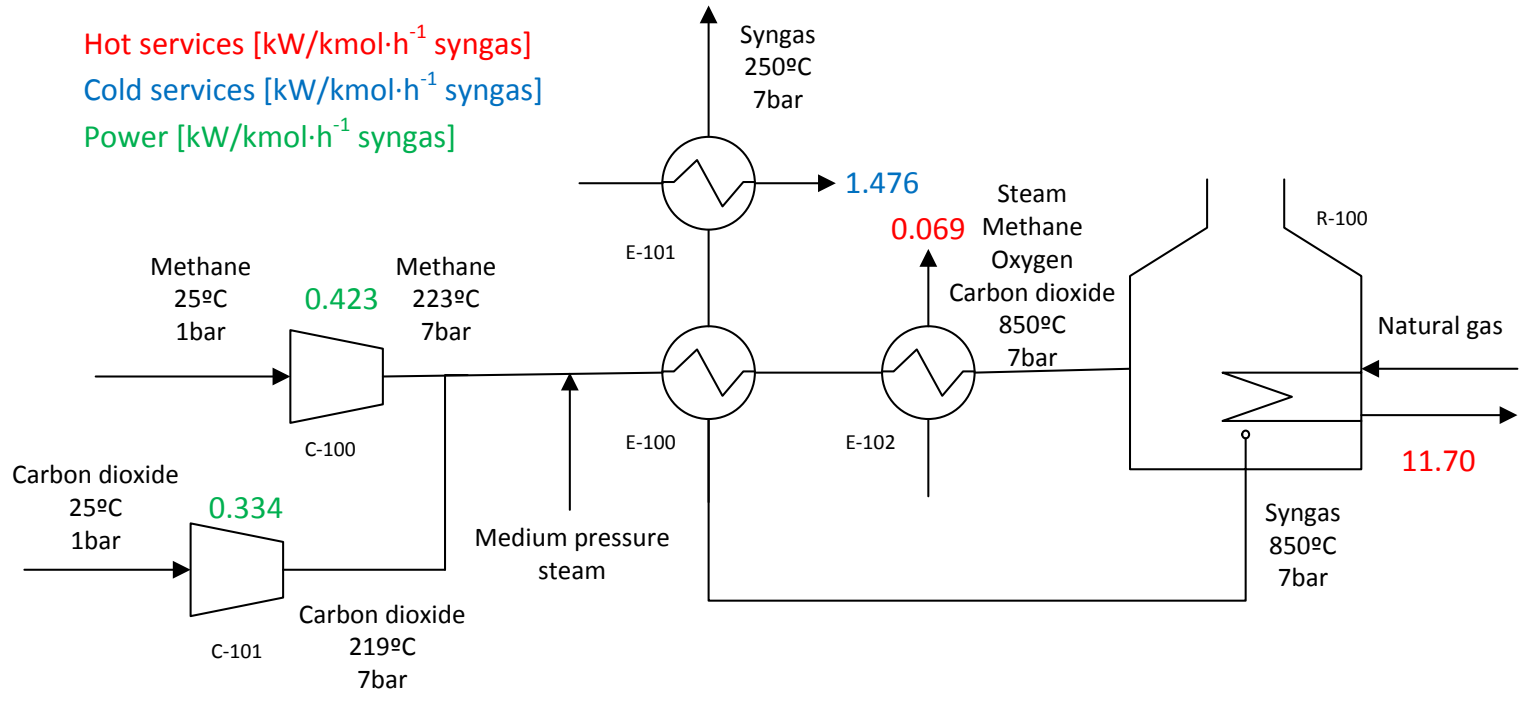

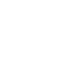

\begin{tabular}{|c|c|c|c|c|c|}
\hline C-100 & C-101 & C-102 & C-103 & C-104 & C-105 \\
\hline compressor & compressor & compressor & compressor & compressor & compressor \\
\hline E-100 & E-101 & E-102 & E-103 & E-104 & R-100 \\
\hline cooler & cooler & cooler & pre-heater & pre-heater & reformer furnace \\
\hline
\end{tabular}

Hot services $\left[\mathrm{kW} / \mathrm{kmol} \cdot \mathrm{h}^{-1}\right.$ syngas] Cold services $\left[\mathrm{kW} / \mathrm{kmol} \cdot \mathrm{h}^{-1}\right.$ syngas]

Power $\left[\mathrm{kW} / \mathrm{kmol} \cdot \mathrm{h}^{-1}\right.$ syngas]

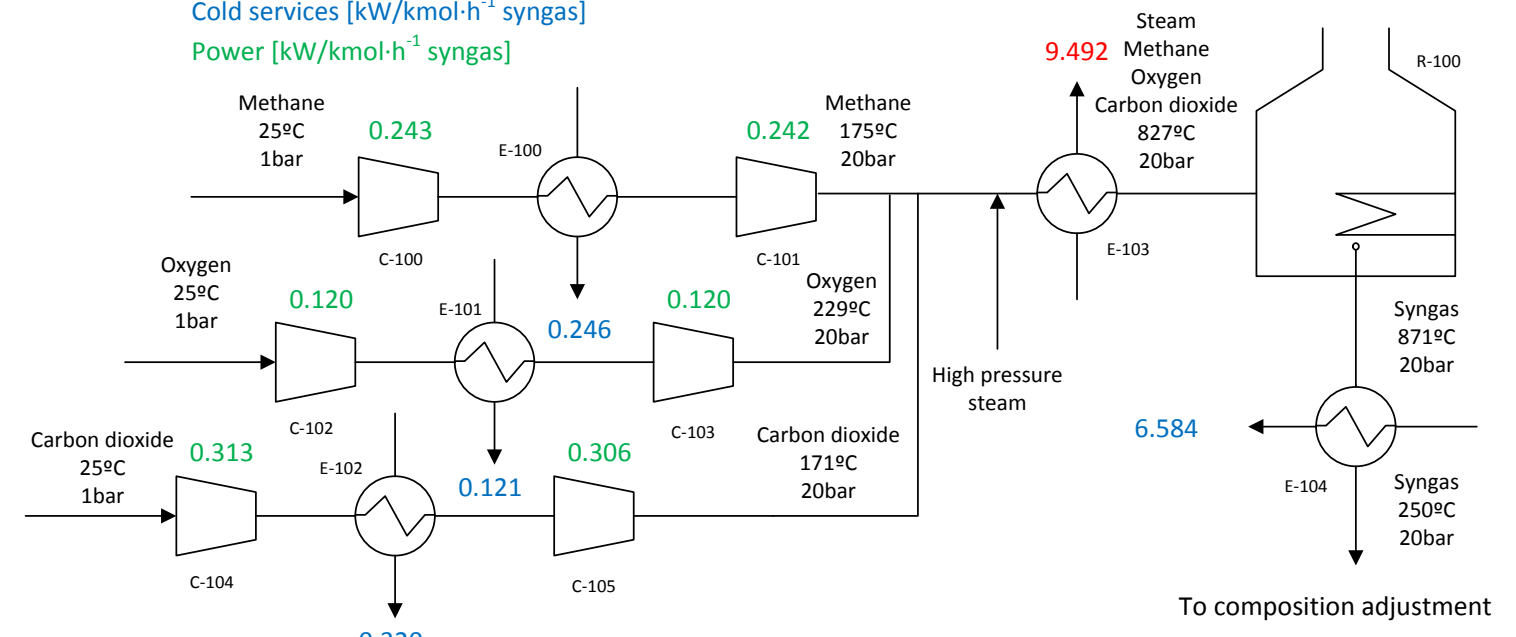

0.320

To composition adjustment 


\begin{tabular}{|c|c|c|c|c|c|c|}
\hline C-100 & C-101 & C-102 & C-103 & C-104 & C-105 & R-100 \\
\hline compressor & compressor & compressor & compressor & compressor & compressor & reformer furnace \\
\hline E-100 & E-101 & E-102 & E-103 & E-104 & E-105 & \\
\hline cooler & cooler & cooler & exchanger & exchanger & pre-heater \\
\cline { 2 - 5 }
\end{tabular}
Cold services $\left[\mathrm{kW} / \mathrm{kmol} \cdot \mathrm{h}^{-1}\right.$ syngas] Power $\left[\mathrm{kW} / \mathrm{kmol} \cdot \mathrm{h}^{-1}\right.$ syngas $]$

739

740

741

742

743

744

745

746

Table B.1. Values of $\chi_{i j}$ in kmol of component $j$ exiting process $i$ per kmol of fresh methane entering the process.

\section{APPENDIX B}

\section{- Calculated parameters used in the optimization}

\begin{tabular}{ccccccc}
\hline & Methane & Steam & $\mathbf{O}_{2}$ & $\mathbf{C O}_{2}$ & $\mathbf{C O}$ & $\mathbf{H}_{2}$ \\
\hline SMR & 0.0912 & 1.8028 & 0.0000 & 0.2882 & 0.6205 & 3.0144 \\
POX & 0.0711 & 0.0591 & 0.0000 & 0.0120 & 0.9168 & 1.7985 \\
ATR & 0.0007 & 1.4205 & 0.0000 & 0.2100 & 0.7892 & 2.0079 \\
CR & 0.0213 & 1.6501 & 0.0000 & 0.2463 & 0.7324 & 2.8069 \\
DMR & 0.0592 & 0.0305 & 0.0000 & 0.0287 & 1.9119 & 1.8508 \\
BR & 0.0735 & 1.0043 & 0.0000 & 0.4691 & 1.2572 & 2.4483 \\
TR & 0.0354 & 2.5248 & 0.0000 & 1.2103 & 1.0541 & 1.8640 \\
\hline
\end{tabular}

747

748 Table B.2. Energetic demand of process $i$ in kWh of utility $u$ per kmol of fresh methane fed to the process.

\begin{tabular}{lccc}
\hline & Power & Cooling water & Natural gas \\
\hline SMR & 3.245 & 7.767 & 55.11 \\
POX & 5.763 & 19.21 & 0.000
\end{tabular}




\begin{tabular}{cccc} 
ATR & 5.768 & 23.21 & 0.000 \\
CR & 4.229 & 2.047 & 43.78 \\
DMR & 0.000 & 0.000 & 77.54 \\
BR & 3.976 & 7.754 & 61.82 \\
TR & 8.989 & 0.521 & 6.245 \\
\hline
\end{tabular}

Table B.3. Emission $\varphi_{i u}$ in kg of $\mathrm{CO}_{2}$-eq emitted of utility $u$ per kmol of methane fed to process $i$.

\begin{tabular}{cccc}
\hline & Power & Cooling water & Natural gas \\
\hline SMR & 1.991 & 0.000 & 33.82 \\
POX & 3.536 & 0.000 & 0.000 \\
ATR & 3.539 & 0.000 & 0.000 \\
CR & 2.595 & 0.000 & 26.87 \\
DMR & 0.000 & 0.000 & 47.58 \\
BR & 2.440 & 0.000 & 37.94 \\
TR & 5.516 & 0.000 & 3.83 \\
\hline
\end{tabular}

751
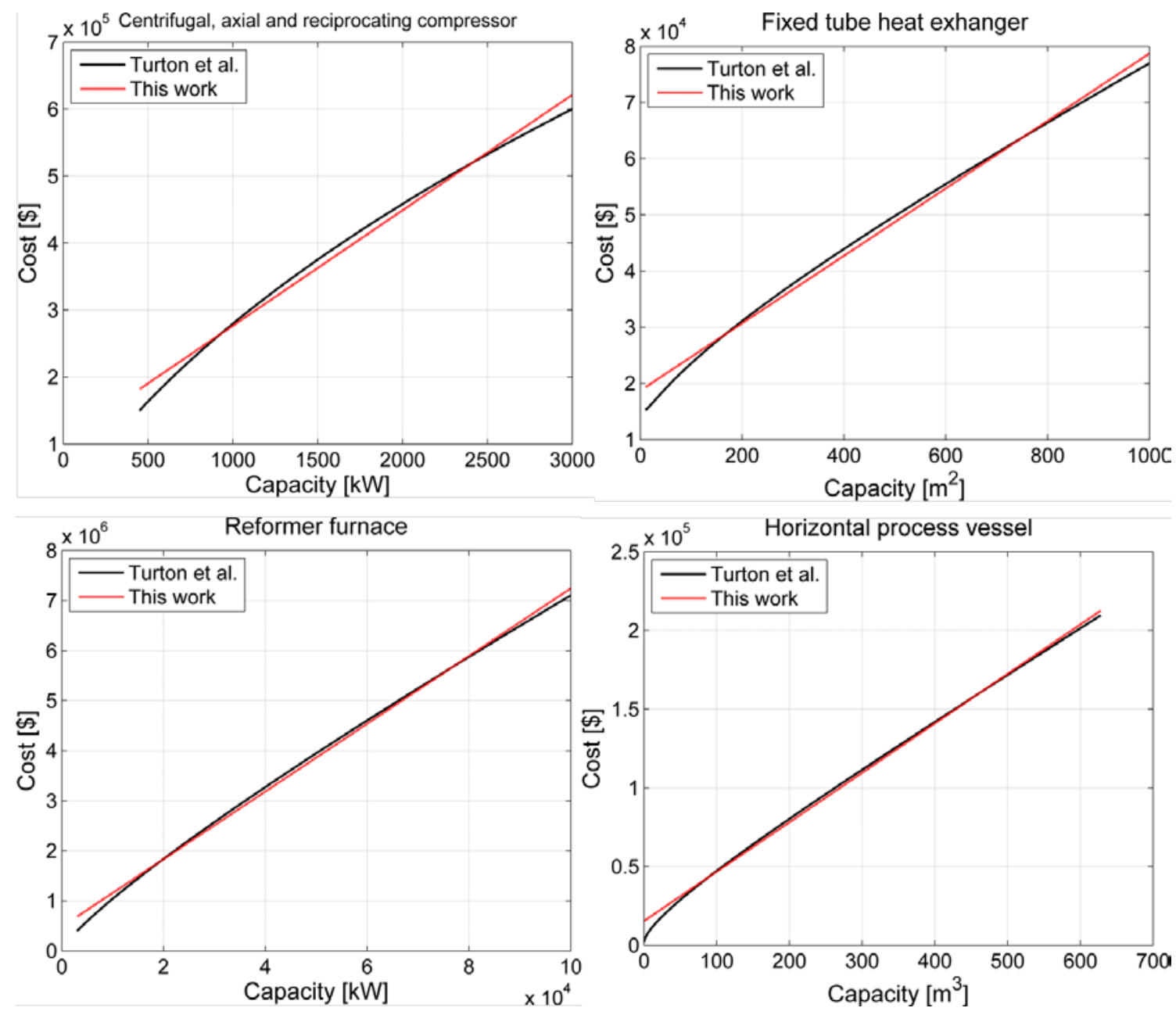
757

758

759

760

761

762
Table B.4. Fixed $c_{i k}^{f}$ and variable $c_{i k}^{v}$ cost parameters of process units shown in Figure B.1.

\begin{tabular}{ccc}
\hline Unit & $C_{i k}^{f} \cdot \mathbf{1 0 ^ { - 4 }}[\$]$ & $C_{i k}^{v}$ [\$/capacity units] \\
\hline Compressor & 10.43 & 172.4 \\
Heat exchanger & 1.871 & 59.99 \\
Reformer furnace & 48.01 & 67.64 \\
Process vessel* & 1.531 & 314.1
\end{tabular}

Figure B.1. Comparison among the original capital cost relations for compressors, heat exchangers, reformer furnaces and process vessels [18] and the work linearization used in this work.

*used for absorber columns, flash separator and WGS reactor. 
769

770

771

772

773

774

775

776

777

778

Table C. 2. Molar flow results [kmol/s] of Figure C.10.

Table C. 2. Molar flow results [kmol/s] of Figure C.10.

\begin{tabular}{cccccccc}
\hline & $\begin{array}{c}\text { POX } \\
\text { inlet }\end{array}$ & $\begin{array}{c}\text { POX } \\
\text { outlet }\end{array}$ & $\begin{array}{c}\text { WGS } \\
\text { inlet }\end{array}$ & $\begin{array}{c}\text { WGS } \\
\text { outlet }\end{array}$ & $\begin{array}{c}\text { Flash } \\
\text { inlet }\end{array}$ & $\begin{array}{c}\text { Flash } \\
\text { outlet }\end{array}$ & $\begin{array}{c}\text { Syngas } \\
\text { Product }\end{array}$ \\
\hline $\begin{array}{c}\text { Methane } \\
\text { Water/Steam }\end{array}$ & 0.331 & 0.024 & 0.005 & 0.005 & 0.024 & 0.024 & 0.024 \\
$\quad-$ & 0.020 & 0.004 & 0.000 & 0.016 & - & - \\
Oxygen & 0.166 & - & & & & & - \\
Carbon dioxide & - & 0.004 & 0.001 & 0.005 & 0.008 & 0.008 & 0.015 \\
$\begin{array}{c}\text { Carbon monoxide } \\
\text { Hydrogen }\end{array}$ & - & 0.304 & 0.062 & 0.058 & 0.300 & 0.300 & 0.300 \\
\hline
\end{tabular}

779

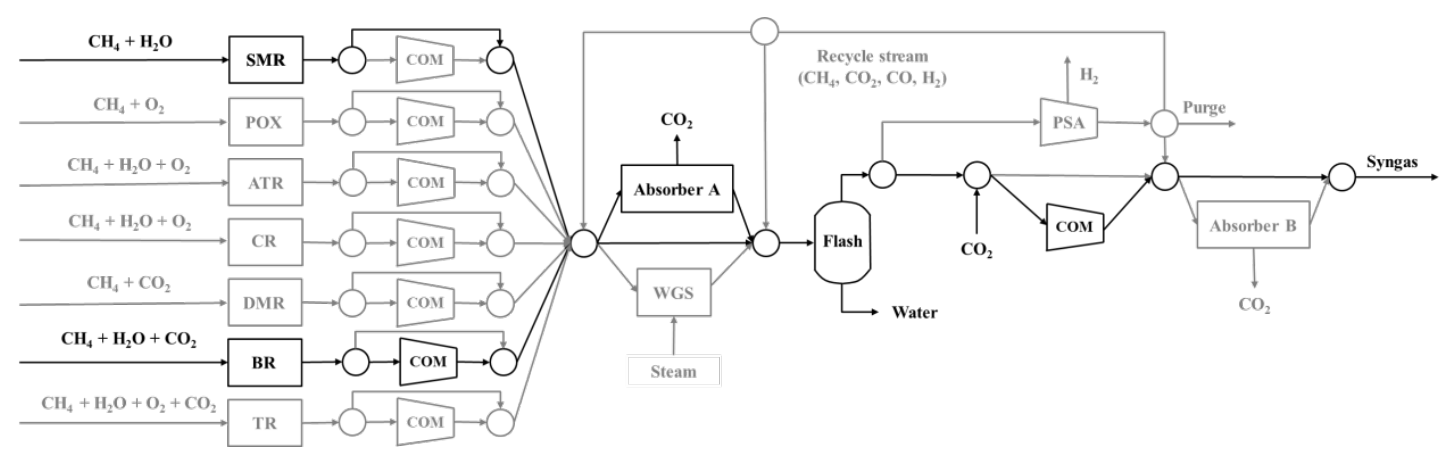

Figure C.11. Flow diagram result from the superstructure optimization for minimum emission for $\left(\mathrm{H}_{2}\right.$ - 
Table C. 3. Molar flow results [kmol/s] of Figure C.11.

\begin{tabular}{cccccccccc}
\hline & $\begin{array}{c}\text { SMR } \\
\text { inlet }\end{array}$ & $\begin{array}{c}\text { SMR } \\
\text { outlet }\end{array}$ & $\begin{array}{c}\text { BR } \\
\text { inlet }\end{array}$ & $\begin{array}{c}\text { BR } \\
\text { outlet }\end{array}$ & $\begin{array}{c}\text { Absorber } \\
\text { inlet }\end{array}$ & $\begin{array}{c}\text { Absorber } \\
\text { outlet }\end{array}$ & $\begin{array}{c}\text { Flash } \\
\text { inlet }\end{array}$ & $\begin{array}{c}\text { Flash } \\
\text { outlet }\end{array}$ & $\begin{array}{c}\text { Syngas } \\
\text { Product }\end{array}$ \\
\hline Methane & 0.258 & 0.023 & 0.111 & 0.008 & 0.003 & 0.003 & 0.032 & 0.032 & 0.032 \\
Water/Steam & 0.774 & 0.465 & 0.178 & 0.112 & 0.058 & 0.058 & 0.577 & - & - \\
$\begin{array}{c}\text { Oxygen } \\
\text { Carbon dioxide }\end{array}$ & - & - & - & - & - & - & - & - & - \\
$\begin{array}{c}\text { Carbon } \\
\text { monoxide }\end{array}$ & - & 0.074 & 0.089 & 0.052 & 0.013 & 0.001 & 0.114 & 0.114 & 0.150 \\
$\begin{array}{c}\text { Hydrogen } \\
\text { Mydron }\end{array}$ & - & 0.777 & - & 0.273 & 0.105 & 0.105 & 1.050 & 1.050 & 1.050 \\
\hline
\end{tabular}

785 